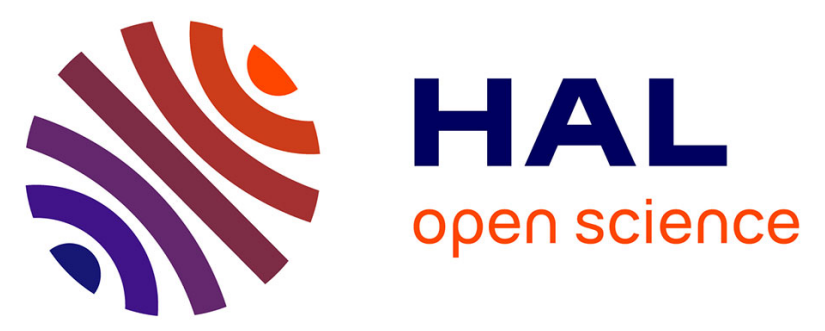

\title{
Tailored mixture properties for accurate laminar flame speed measurement from spherically expanding flames: Application to $\mathrm{H} 2$ /O 2 / N 2 /He mixtures
}

Yakun Zhang, Marine Jeanson, Rémy Mével, Zheng Chen, Nabiha Chaumeix

\section{- To cite this version:}

Yakun Zhang, Marine Jeanson, Rémy Mével, Zheng Chen, Nabiha Chaumeix. Tailored mixture properties for accurate laminar flame speed measurement from spherically expanding flames: Application to $\mathrm{H} 2 / \mathrm{O} 2 / \mathrm{N} 2$ /He mixtures. Combustion and Flame, 2021, 231, pp.111487. 10.1016/j.combustflame.2021.111487 . hal-03455835

\author{
HAL Id: hal-03455835 \\ https://hal.science/hal-03455835
}

Submitted on 29 Nov 2021

HAL is a multi-disciplinary open access archive for the deposit and dissemination of scientific research documents, whether they are published or not. The documents may come from teaching and research institutions in France or abroad, or from public or private research centers.
L'archive ouverte pluridisciplinaire HAL, est destinée au dépôt et à la diffusion de documents scientifiques de niveau recherche, publiés ou non, émanant des établissements d'enseignement et de recherche français ou étrangers, des laboratoires publics ou privés. 
See discussions, stats, and author profiles for this publication at: https://www.researchgate.net/publication/351293429

Tailored Mixture Properties for Accurate Laminar Flame Speed Measurement from Spherically Expanding Flames: Application to $\mathrm{H}_{2} / \mathrm{O} 2 / \mathrm{N} 2$ /He Mixtures

Article in Combustion and Flame · May 2021

DOI: 10.1016/j.combustflame.2021.111487

\section{CITATION}

1

5 authors, including:

A Yakun Zhang

Tsinghua University

3 PUBLICATIONS 1 CITATION

SEE PROFILE

Zheng Chen

Peking University

118 PUBLICATIONS 4,559 CITATIONS

SEE PROFILE

Some of the authors of this publication are also working on these related projects:

Project Ignition regime View project

Project droplet vaporizatioin View project
152

R. Mével

Tsinghua University

147 PUBLICATIONS 963 CITATIONS

SEE PROFILE

Nabiha Chaumeix

CNRS Orleans Campus

133 PUBLICATIONS 2,212 CITATIONS

SEE PROFILE 


\title{
Tailored Mixture Properties for Accurate Laminar Flame Speed Measurement from Spherically Expanding Flames: Application to $\mathrm{H}_{2} / \mathrm{O}_{2} / \mathrm{N}_{2} / \mathrm{He}$ Mixtures
}

\author{
Yakun Zhanga, Marine Jeanson ${ }^{\mathrm{b}}$, Rémy Mével ${ }^{\mathrm{a}, *}$, Zheng Chen ${ }^{\mathrm{c}, *}$, Nabiha \\ Chaumeix $^{\mathrm{b}, *}$ \\ ${ }^{a}$ Center for Combustion Energy, School of Vehicle and Mobility, State Key Laboratory for \\ Automotive Safety and Energy, Tsinghua University, Beijing, China \\ ${ }^{b}$ CNRS-INSIS, I.C.A.R.E., 1C, Avenue de la recherche scientifique, 45071 Orléans cedex 2, \\ France \\ ${ }^{c}$ SKLTCS, CAPT, Department of Mechanics and Engineering Science, College of Engineering, \\ Peking University, Beijing 100871, China
}

\begin{abstract}
The uncertainty on the laminar flame speed extracted from spherically expanding flames can be minimized by using large flame radius data for the extrapolation to zero stretch-rate. However, at large radii, the hydrodynamic and thermo-diffusive instabilities would induce the wrinkling of the flame surface and limit the range of usable data. In the present study, we have employed the flame stability theory of Matalon to tailor the properties of the initial mixture so that onset of cellular flame would occur at a pre-determined, large radius. This approach was employed to measure the laminar flame speeds of $\mathrm{H}_{2} / \mathrm{O}_{2} / \mathrm{N}_{2} / \mathrm{He}$ mixtures with equivalence ratios from 0.6 to 2.0 , at pressures of $50 / 80 / 100 \mathrm{kPa}$ and initial temperature of 300 K. For most experiments we performed, the uncertainty related to the extrapolation to zero stretch-rate (performed with the linear curvature model) was below $2 \%$ as shown by the position of the data points in the $\left(\mathrm{L}_{b} / \mathrm{R}_{f, U}, \mathrm{~L}_{b} / \mathrm{R}_{f, L}\right)$ plan, where $\mathrm{L}_{b}$ is the burned Markstein length; and $\mathrm{R}_{f, L}$ and $\mathrm{R}_{f, U}$ are the flame radii at the lower and upper bounds of the extrapolation range. Unsteady 1-D simulations using four chemical mechanisms were performed to show that unstretched laminar flame speed can be well-characterized with relative error below $10 \%$ for most conditions. The flame dynamical response to stretch rate could be captured by the mechanisms only
\end{abstract}

\footnotetext{
${ }^{*}$ Corresponding author: mevel@mail.tsinghua.edu.cn
} 
under some conditions. Further analyses on critical flame radius were carried out: (i) the dominant parameters were identified based on a local sensitivity analysis; and (ii) the uncertainty on the predicted critical radius was determined through an uncertainty propagation approach. Uncertainty in critical flame radius calculation comes mostly from the uncertainty on fundamental transport and kinetic data. The present work indicates that although the stability theory of Matalon provides a well defined framework to tailor the mixture properties for improved flame speed measurement, the inaccuracy of some of the required parameters can result in significantly over-estimated critical radius for cellular flame onset which compromises the accuracy of the tailoring procedure.

Keywords: Spherical expanding flame, Critical flame radius, Laminar flame speed, Uncertainty propagation

\section{Introduction}

The laminar flame speed, $S_{u}^{0}$, is defined as the normal propagation velocity of fresh gas relative to a fixed, planar flame front [1]. It contains the physicochemical information of the reactive mixture and helps in characterizing combustion phenomena, testing and validating reaction models $[2,3]$. Furthermore, since turbulent combustion properties scale with the laminar ones $[4,5]$, accurate experimental data obtained under laminar conditions are needed to predict turbulent combustion which is relevant to the conditions found in real applications, such as internal combustion engine, gas turbine and accidental explosion [4-6]. Various methods have been developed to measure $S_{u}^{0}$ including Bunsen flame, counterflow/stagnation flame, burner stabilized flat flame and spherically expanding flame (SEF). The advantages, limitations and technical updates of these methods have been reviewed in detail by Egolfopoulos et al. and Konnov et al. [1, 2]. Among these methods, the SEF method is widely employed because it is the most effective method for measuring $S_{u}^{0}$ at engine-relevant conditions especially at elevated pressure [7]. Using the SEF method along with a high-speed visualization system, the laminar flame speed can be extrapolated to zero-stretch rate from the temporal evolution of the radius $R_{f}(t)$ of a centrally spark-ignited flame. 
Substantial efforts have been made to reduce the uncertainty associated with laminar flame speed measurement using the SEF method [1, 8-10]. Possible perturbations for a laminar spherical flame propagating in a constant volume bomb have been summarized by Lipatnikov et al. [9]. These perturbations include (i) spark ignition effects, (ii) confinement effects, (iii) heat loss through radiation, (iv) nonuniformity of product density, (v) compression effects of unburned gas and products, (vi) flame instabilities and (vii) stretch effects. The uncertainties induced by these perturbations have been quantified and their contributions to $S_{u}^{0}$ deviations have been investigated in [11-16]. In order to decrease the influence of the aforementioned perturbations, various approaches have been developed $[1,8]$. However, the approach of excluding data points that have been obviously influenced by the perturbations is simple and widely used for significantly mitigating the perturbations $[9,17]$. Perturbations (i) and (iv) only affect spherical flames at early stages and consequently these small radius data can be removed from the $R_{f}(t)$ curve. Perturbations (ii) and (v) are related to large flame radii with respect to the characteristic length scale of the combustion vessel and the part of the $R_{f}(t)$ curve affected by these two perturbations can be readily excluded from the analysis. Perturbation (iii) is relevant to slow flames at very large radius, so that many conditions can be studied without considering this perturbation. For near flammability limit or decomposition flames [18], which demonstrate low propagation velocity, empirical correlations [19] are available to estimate the increased uncertainty on the flame speed. Perturbations (vi) and (vii) are by far the most challenging especially when targeting a wide range of pressure for the measurements.

The effect of stretch rate on the flame propagation can be described using various linear or non-linear extrapolation equations [20-22] which enable to extract the unstretched laminar flame speed. Nevertheless, Wu et al. [23] showed that the selection of extrapolation equations is one of the major causes to data discrepancy. It was found that substantial errors resulting from extrapolation still exist for conditions where the Lewis number $(L e)$ is away from unity, as for very lean or rich 
hydrogen/air flames [23, 24]. Recent studies [23, 25, 26] have explored the effect of flame radius range on the uncertainty resulting from the extrapolation method and showed that extrapolation-induced uncertainty can be reduced using large flame radius data. In particular, Huo et al. [26] found that extrapolation uncertainty largely relates to the Markstein length $\left(L_{b}\right)$ normalized by the flame radius $\left(R_{f}\right)$ and the uncertainty can be limited to a maximum of $2 \%$ using flame radius from $3 \mathrm{~cm}$ to 4 $\mathrm{cm}$. However, the use of large flame radii for measuring the flame speed increases the detrimental impact of perturbation (vi). The flame instability, which results in the formation of cellular structures on the flame surface, is induced, on the one hand, by the gas expansion across the flame front (hydrodynamic or Darrieus-Landau instability), and on the other hand, by the non-equidiffusion of mass and heat of the deficient reactant (thermo-diffusive instability).

The strategy to mitigate the development of cellular instabilities consists of using helium as diluant in the combustible mixture. With the addition of helium, hydrodynamic instability can be suppressed by the increasing flame thickness, especially at high pressures; thermo-diffusive instability can be mitigated by increasing the effective Lewis number $\left(L e_{e f f}\right)$ of the mixture. This approach has been implemented by several groups [27-32] at normal and elevated pressures and temperatures. It is worth mentioning that few well-defined procedure has been proposed to minimize the uncertainty related to perturbations (vi) and (vii) through tailoring the mixture property.

In view of these considerations, the goal of the present study is to develop a procedure to tailor the mixture properties based on the flame stability theory of Matalon et al. [33], so that the theoretical onset of instability for SEF is delayed up to a predefined large flame radius, thus allowing to perform the flame speed measurement over a wide range of radii for which the uncertainty associated with the extrapolation method can be minimized. The procedure was applied to hydrogenair mixtures over a range of pressures from 50 to $100 \mathrm{kPa}$, equivalence ratios $(\Phi)$ from 0.6 to 2.0 and initial temperature of $300 \mathrm{~K}$. Theoretical and experimental 
flame properties were compared to evaluate the performance of the flame stability theory and four chemical mechanisms. Then, theoretical analyses focused on critical flame radius $\left(R_{c}\right)$ were implemented. The influence of changing flame property on the prediction of $R_{c}$ were explored through local sensitivity analysis. Uncertainty propagation for some fundamental parameters in the input kinetics, thermodynamics and transport data sets was investigated and quantified.

\section{Materials and methods}

\subsection{Tailoring procedure}

The onset of instability for SEF was first theoretically described by Istratov et al. [34] considering only the hydrodynamic effect. Bechtold and Matalon [35] extended the stability analysis accounting for both hydrodynamic and thermo-diffusive instabilities. Addabbo et al. [33] further improved the stability analysis using more realistic temperature-dependent transport coefficients and the theory was applied in [36]. According to the theory of spherical flame stability of Matalon and coworkers $[33,37]$, the critical flame radius for cellularity onset $\left(R_{c}\right)$ is given by

$$
R_{c}=\delta \cdot P e_{c}=\delta \cdot \frac{\Omega}{\omega}=\frac{\delta}{\omega}\left(Q_{1}+\frac{\beta\left(L e_{e f f}-1\right)}{\sigma_{e}-1} Q_{2}+\operatorname{Pr} Q_{3}\right),
$$

where $\delta$ is the flame thickness; $P e_{c}$ is the critical Peclet number; $\omega$ corresponds to the contribution of the hydrodynamic effects to the flame instability; $\Omega$ corresponds to the contribution of thermo-diffusive effect to the flame instability; $\beta$ is the Zeldovich number; $L e_{e f f}$ is the effective Lewis number; $\sigma_{e}=T_{a d} / T_{u}$ is the expansion ratio where $T_{a d}$ is the adiabatic flame temperature and $T_{u}$ is the unburnt gas temperature; $\operatorname{Pr}$ is the Prandtl number; $Q_{1}, Q_{2}$, and $Q_{3}$ are complex terms which depend on the expansion ratio, the spherical harmonic wavenumber $(n)$, and the thermal conductivity $(\lambda)$, see supplementary material for detailed equations. The flame thickness is calculated using the temperature gradient definition

$$
\delta=\frac{T_{a d}-T_{u}}{(d T / d x)_{\max }},
$$


where $(d T / d x)_{\max }$ is the maximum temperature gradient in a steady 1-D planar flame. The Zeldovich number $\beta$ is defined as

$$
\beta=E_{a} \frac{T_{a d}-T_{u}}{R T_{a d}^{2}},
$$

where $E_{a}$ is the activation energy and $R$ is the perfect gas constant. $E_{a}$ is determined by

$$
E_{a}=-2 R\left\{\frac{\partial\left[\ln \left(m^{0}\right)\right]}{\partial\left[\ln \left(1 / T_{a d}\right)\right]}\right\},
$$

where $m^{0}$ is the mass burning rate. $m^{0}$ and $T_{a d}$ for mixtures with different mole fractions of argon $(0 \%, 1 \%, 2 \%, 3 \%, 4 \%, 5 \%)$ were used to calculate the partial difference in Equation 4. To reduce the computational costs, the relationship between $E_{a}$ and helium percentage in the dilution was fitted using a quadratic polynomial prior to the tailoring procedure. The effective Lewis number $L e_{e f f}$ is obtained from

$$
L e_{e f f}=1+\frac{\left(L e_{E}-1\right)+\left(L e_{D}-1\right) \varepsilon}{1+\varepsilon}
$$

where $\varepsilon=1+\beta(\Xi-1)$ with $\Xi=\Phi$ for rich mixtures and $\Xi=1 / \Phi$ for lean mixtures. All the required parameters were calculated using the thermo-chemical and transport utilities available in the Cantera package [38].

The tailoring procedure is described in Fig. 1. First, a target critical radius $\left(R_{c}^{t}\right)$ is defined. Then, the theoretical critical radius $\left(R_{c}^{t h}\right)$ is calculated for $\mathrm{H}_{2}$-air mixture. If $R_{c}^{t h}$ is greater than or equal to $R_{c}^{t}$, the tailoring procedure is stopped. If $R_{c}^{t h}$ is lower than $R_{c}^{t}, \mathrm{~N}_{2}$ would be fully replaced by helium, while the mole fraction of other components remain unchanged. We define $R_{c}^{t h}(H e)$ as the corresponding critical flame radius for the $\mathrm{H}_{2} / \mathrm{O}_{2} / \mathrm{He}$ mixture. If $R_{c}^{t h}(\mathrm{He})$ is greater than or equal to $R_{c}^{t}$, considering the initial mixture composition, $\mathrm{N}_{2}$ would be partly replaced by helium. If $R_{c}^{t h}(H e)$ is less than $R_{c}^{t}$, the hydrogen to oxygen ratio would be maintained, and the mole fraction of the diluant (including only helium) is increased. Through iteration, the tailored composition with theoretical $R_{c}$ equal to the pre-defined radius can be obtained using a Matlab routine in order to measure the flame speed at large flame radii. This procedure was applied to $\mathrm{H}_{2}$-air mixture using Wang's model [39] (14 species and 38 reactions). The initial temperature was set at $300 \mathrm{~K}$. The pressure 
was considered as constant during flame propagation at 50/80/100 kPa. The optical window radius of the experimental combustion vessel, $10 \mathrm{~cm}$, was selected as $R_{c}^{t}$. The evolution of $R_{c}^{t h}$ as a function of the proportion of helium is shown in Fig. 2 for mixtures initially at $\mathrm{P}=100 \mathrm{kPa}, \mathrm{T}=300 \mathrm{~K}$, and $\Phi=0.6-2.0$. The intersection between $R_{c}^{t h}=\mathrm{f}\left(X_{H e} /\left(X_{H e}+X_{N 2}\right)\right)$ and $R_{c}^{t}=10 \mathrm{~cm}$ corresponds to the tailored mixture composition. The tailored compositions of the mixtures we studied experimentally are given in Table 1.

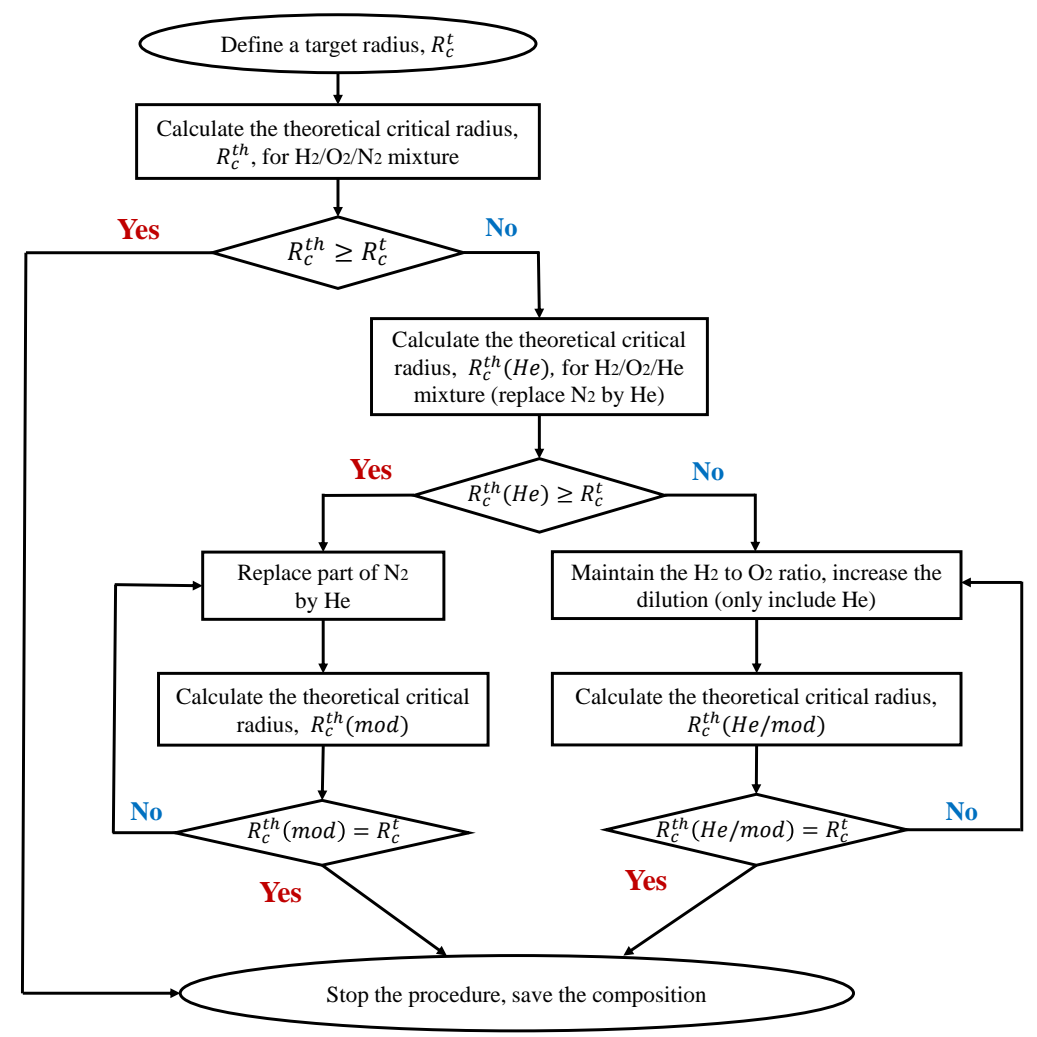

Fig. 1. The flow chart of tailoring procedure for $\mathrm{H}_{2} / \mathrm{O}_{2} / \mathrm{N}_{2} / \mathrm{He}$ mixture.

\subsection{Experimental methodology}

\subsubsection{Experimental set-up}

Experiments of SEF were carried out in a constant volume vessel. Detailed description of the apparatus has been given in [40] so only a brief introduction is given here. It is a stainless steel spherical bomb with an inner diameter of $563 \mathrm{~mm}$. It can sustain a maximum pressure of $20 \mathrm{MPa}$ and can be heated up to $573 \mathrm{~K}$. It is 
Table 1: Composition of the $\mathrm{H}_{2} / \mathrm{O}_{2} / \mathrm{N}_{2} / \mathrm{He}$ mixtures. The initial conditions, the measured parameters, and some calculated parameters are also given.

\begin{tabular}{ccccccccccc}
\hline$\Phi$ & $\mathrm{X}_{H_{2}}$ & $\mathrm{X}_{O_{2}}$ & $\mathrm{X}_{N_{2}}$ & $\mathrm{X}_{H e}$ & $\mathrm{P}_{1}(k P a)$ & $\mathrm{T}_{1}(\mathrm{~K})$ & $R_{c}^{e x}(\mathrm{~cm})$ & $R_{c}^{\text {th }}(\mathrm{cm})$ & $S_{u}^{0}(\mathrm{~cm} / \mathrm{s})$ & $L_{b}(\mathrm{~mm})$ \\
\hline 0.6 & 0.201 & 0.168 & 0.146 & 0.485 & 100 & 297 & 7.1 & 10.00 & 202 & 0.43 \\
0.8 & 0.252 & 0.157 & 0.266 & 0.325 & 100 & 295 & 7.0 & 10.00 & 250 & 1.01 \\
1.0 & 0.296 & 0.148 & 0.379 & 0.177 & 100 & 295 & 5.6 & 10.00 & 265 & 0.89 \\
1.2 & 0.335 & 0.140 & 0.412 & 0.114 & 100 & 294 & 7.0 & 10.00 & 295 & 1.07 \\
1.5 & 0.387 & 0.129 & 0.404 & 0.080 & 100 & 296 & 7.7 & 10.03 & 311 & 0.77 \\
2.0 & 0.457 & 0.114 & 0.429 & 0.000 & 100 & 295 & 8.7 & 10.31 & 290 & 0.68 \\
\hline 0.6 & 0.201 & 0.168 & 0.286 & 0.345 & 80 & 297 & 4.7 & 10.00 & 163 & 0.17 \\
0.8 & 0.252 & 0.157 & 0.435 & 0.156 & 80 & 296 & 7.4 & 10.08 & 196 & 0.63 \\
1.0 & 0.296 & 0.148 & 0.556 & 0.000 & 80 & 295 & 6.7 & 10.28 & 217 & 0.79 \\
1.2 & 0.335 & 0.140 & 0.525 & 0.000 & 80 & 297 & 7.6 & 11.35 & 250 & 0.87 \\
1.5 & 0.387 & 0.129 & 0.485 & 0.000 & 80 & 295 & 7.7 & 11.77 & 276 & 0.72 \\
2.0 & 0.457 & 0.114 & 0.429 & 0.000 & 80 & 296 & 7.4 & 13.37 & 277 & 0.71 \\
\hline 0.6 & 0.201 & 0.168 & 0.506 & 0.125 & 50 & 297 & 7.3 & 10.00 & 115 & -0.42 \\
0.8 & 0.252 & 0.157 & 0.591 & 0.000 & 50 & 299 & 7.8 & 13.01 & 157 & 0.36 \\
1.0 & 0.296 & 0.148 & 0.556 & 0.000 & 50 & 295 & 7.7 & 18.33 & 202 & 0.87 \\
1.2 & 0.335 & 0.140 & 0.525 & 0.000 & 50 & 297 & 5.8 & 20.20 & 240 & 0.94 \\
1.5 & 0.387 & 0.129 & 0.485 & 0.000 & 50 & 296 & 7.3 & 20.92 & 265 & 0.97 \\
2.0 & 0.457 & 0.114 & 0.429 & 0.000 & 50 & 296 & 8.6 & 23.55 & 273 & 1.37 \\
\hline
\end{tabular}




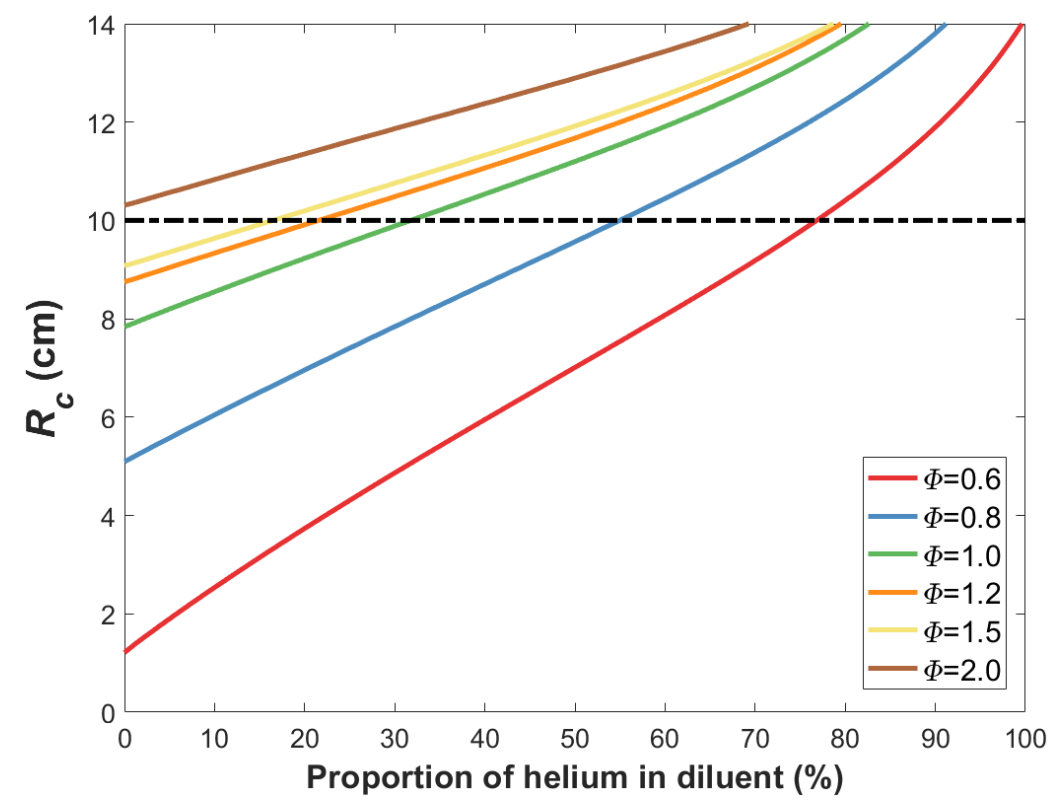

Fig. 2. Theoretical critical radius for $\mathrm{H}_{2} / \mathrm{O}_{2} / \mathrm{N}_{2} / \mathrm{He}$ mixtures with different helium proportion. Conditions: $\mathrm{P}=100 \mathrm{kPa}, \mathrm{T}=300 \mathrm{~K}, \Phi=0.6-2.0$.

equipped with 4 quartz windows with $200 \mathrm{~mm}$ optical diameter for visual access and 8 ports for mounting fans to create homogeneous environment or turbulent conditions. A Z-type schlieren arrangement is utilized. The flame propagation is recorded using a high-speed camera (PHANTOM V1210 or V1610), with an acquisition rate up to 25,000 frames per second. Two tungsten electrodes linked to a high voltage power supply enable to ignite the mixture with a central electric spark. The spherical vessel is equipped with two Kistler piezo-electric pressure transducers (6001 and 601A models) synchronized with the imaging system to ensure that the pressure remains constant during the period employed to extract the flame speed. Prior to each test, the vessel is evacuated to a residual pressure on the order of $1 \mathrm{~Pa}$. The reactive mixtures are prepared using the partial pressure approach. After introducing all the gases needed, the fans are turned on for 3 minutes. Then, the gas is let to settle for 3 minutes before ignition. Example schlieren images of SEF are shown in Fig. 3. By repeating the $\mathrm{SEF}$ experiments at similar conditions for two tailored cases $(\mathrm{P}=50$ $\mathrm{kPa}, \Phi=1.0$ and $\mathrm{P}=100 \mathrm{kPa}, \Phi=0.8)$, the repeatability of experimental results could be characterized, see supplementary material. 

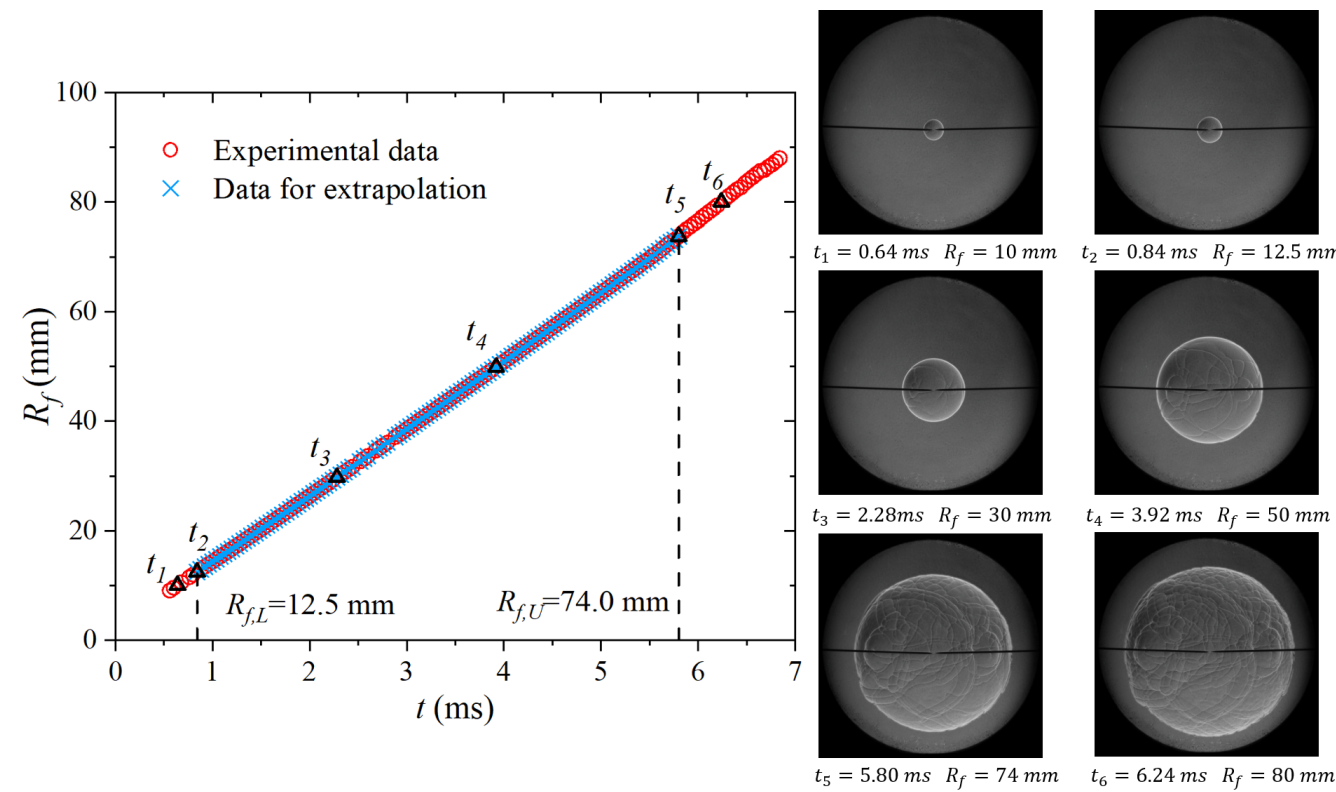

Fig. 3. Evolution of flame radius as a function of time. Conditions: $\mathrm{H}_{2} / \mathrm{O}_{2} / \mathrm{N}_{2} / \mathrm{He}$ mixture, $\Phi=1.5, \mathrm{P}=80 \mathrm{kPa}, \mathrm{T}=296 \mathrm{~K}$ (same experiment as in Fig. 4 (d))

\subsubsection{Data reduction}

To obtain the evolution of the flame radius as a function of time, the raw Schlieren images were processed using an in-house Matlab program that detects the flame edge thus allowing to extract the flame radius profile with time. Further details about this laminar flame analysis program can be found in [25, 41]. The unstretched laminar flame speed was extracted using the linear curvature (LC) equation which considers a linear relationship between the flame speed and curvature

$$
S_{b}=S_{b}^{0}-2 S_{b}^{0} L_{b} / R_{f}
$$

where $S_{b}$ is the stretched flame speed with respect to the burnt gas; $S_{b}^{0}$ is the unstretched flame speed with respect to the burnt gas; and $L_{b}$ is the Markstein length. The choice of the LC equation was motivated by the results in $[8,22,23]$ which showed that this equation is the most accurate to extract the flame speed for mixtures with Lewis number larger than unity. To avoid differentiating the experimental data, numerical integration of Equation 6 is used for extracting the flame properties.

Due to the effect of ignition energy and cellular flame formation, the range of 
data used for extrapolating the unstretched flame speed should be appropriately selected. The effect of minimum and maximum flame radius $\left(R_{f, L}\right.$ and $\left.R_{f, U}\right)$ on the flame properties was investigated. The extrapolation surfaces of $S_{u}^{0}$ using different $R_{f, L}$ and $R_{f, U}$ are shown in Fig. 4 . The shapes of the $L_{b}$ surfaces are similar to the corresponding $S_{u}^{0}$ surfaces, see supplementary material. From Fig. 4 (a), we can see the surface folding along the $R_{f, U}$ axis induced by cellular onset resulting from the dynamics of the cells which demonstrate alternative phases of growth and breakup [42, 43]; in Fig. 4 (b), we can observe the crest along the $R_{f, L}$ axis induced by ignition effect; combination of the two aforementioned effects is shown in Fig. 4 (c); in Fig. 4 (d), the surface is smoother than the first three surfaces. In addition to the obvious oscillations, wavy surfaces with small oscillations are present for all the cases due to noise. Probability density profile was obtained using the data points in the surfaces. Then the profile was fitted to a normal distribution. A one-standard deviation range $\left(\left[\mu_{s}-\sigma_{s}, \mu_{s}+\sigma_{s}\right]\right.$, we call it $1-\sigma_{s}$ range $)$ in $S_{u}^{0}$ was considered to guide the choice of flame radius range, see Fig. 5 (a). Three rules were employed in the $R_{f, L}$ and $R_{f, U}$ determination:

- $R_{f, L}$ and $R_{f, U}$ were fixed at the radius not affected by the obvious oscillations if folding or crest existed in the surface.

- If the surface is wavy with small oscillations, $R_{f, L}$ and $R_{f, U}$ were selected within the $1-\sigma_{s}$ range. $R_{f, L}$ and $R_{f, U}$ correspond to the points starting to deviate from the $1-\sigma_{s}$ range.

- The minimum range of radius was selected to be $20 \mathrm{~mm}$.

An example of $R_{f, L}$ and $R_{f, U}$ selections is shown in Fig. 5. After removing data outside $1-\sigma_{s}$ range, the mean value and standard deviation decreased. For Fig. 5 (b), colored area includes data points in $1-\sigma_{s}$ range, other areas are not considered due to the limitations of minimum radius range and $1-\sigma_{s}$ range. Then, the data points in part of the extrapolation surface we selected were fitted to a normal distribution to extract laminar flame properties and their uncertainties. 


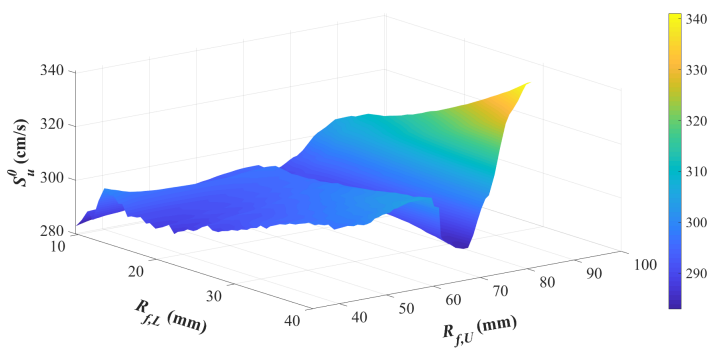

(a)

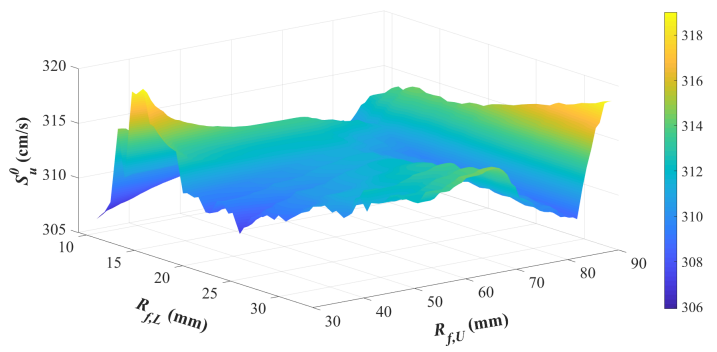

(c)

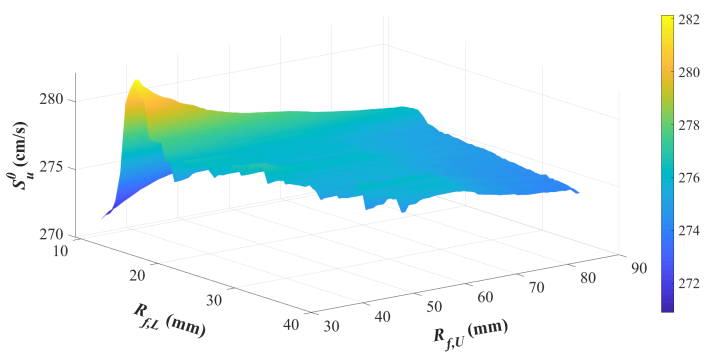

(b)

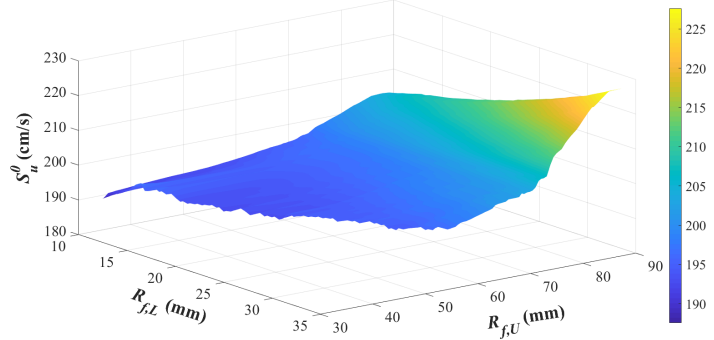

(d)

Fig. 4. Extrapolation surfaces of $S_{u}^{0}$ using different $R_{f, L}$ and $R_{f, U}$. Conditions: (a) tailored $\mathrm{H}_{2} / \mathrm{O}_{2} / \mathrm{N}_{2} / \mathrm{He}$ mixture, $\Phi=1.2, \mathrm{P}=100 \mathrm{kPa}, \mathrm{T}=294 \mathrm{~K}$; (b) $\mathrm{H}_{2} /$ air mixture, $\Phi=1.5, \mathrm{P}=80$ $\mathrm{kPa}, \mathrm{T}=295 \mathrm{~K}$; (c) tailored $\mathrm{H}_{2} / \mathrm{O}_{2} / \mathrm{N}_{2} / \mathrm{He}$ mixture, $\Phi=1.5, \mathrm{P}=100 \mathrm{kPa}, \mathrm{T}=296 \mathrm{~K}$; (d) tailored $\mathrm{H}_{2} / \mathrm{O}_{2} / \mathrm{N}_{2} /$ He mixture, $\Phi=0.8, \mathrm{P}=80 \mathrm{kPa}, \mathrm{T}=296 \mathrm{~K}$.

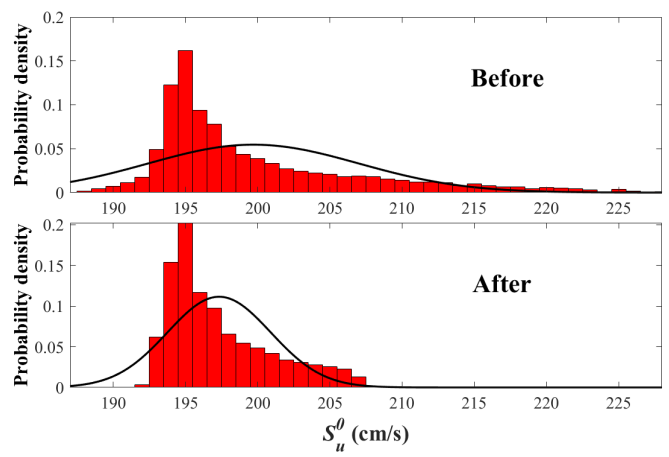

(a)

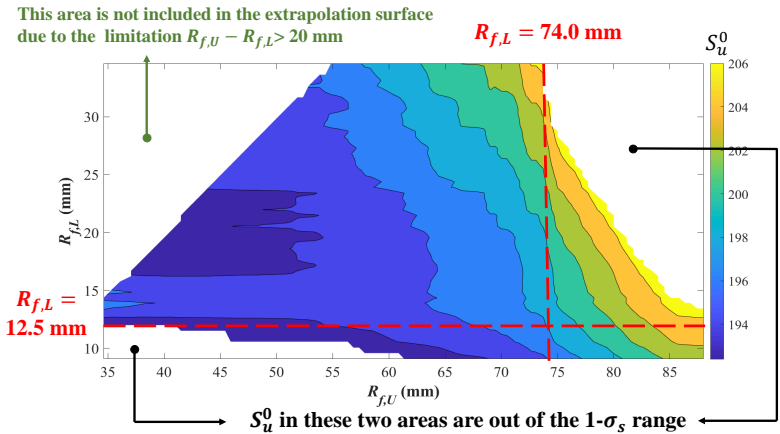

(b)

Fig. 5. (a) Probability density and fitted Gaussian distribution for $S_{u}^{0}$ surface before and after removal of data outside $\left[\mu_{s}-\sigma_{s}, \mu_{s}+\sigma_{s}\right]$ range. (b) Flame radius range determination for $S_{u}^{0}$ wavy surface. Conditions: $\mathrm{H}_{2} / \mathrm{O}_{2} / \mathrm{N}_{2} / \mathrm{He}$ mixture, $\Phi=1.5, \mathrm{P}=80 \mathrm{kPa}, \mathrm{T}=296 \mathrm{~K}$ (same experiment as in Fig. 4 (d)) 


\subsection{Numerical methods}

\subsubsection{Spherical flame simulation}

The simulations of SEF were conducted using the A-SURF code, which has been validated and successfully used in previous studies $[11,14]$. The initial velocity and temperature at each grip point before ignition were set as $0 \mathrm{~cm} / \mathrm{s}$ and $300 \mathrm{~K}$. To avoid perturbation due to confinement effects, the radius of the spherical numerical domain was set at $120 \mathrm{~cm}$. The flame front was defined as the position of maximum heat release rate. The flame radius range used for determining the laminar flame speed and the Markstein length was consistent with the corresponding experiments. The radiation effect was neglected. Mixture-averaged transport and Soret effects were included. In order to explore the effect of chemical mechanisms on the calculation of $S_{b}^{0}$ and $L_{b}$, besides Wang's model, three other mechanisms were also used: Konnov's model [44] (15 species and 75 reactions); Burke's model [45] (13 species and 27 reactions); and Curran's model [46] (11 species and 21 reactions).

\subsubsection{Local sensitivity analysis}

Local sensitivity analysis can be used to determine the influence of changes in model input parameters on the output parameter. This method is the most frequently applied method in combustion research for identifying key reaction pathways and reactants which control model outputs or product distribution [47]. Laminar flame speed is a commonly used model output in mechanism construction and reduction $[48,49]$. In the present study, we performed a local sensitivity analysis on $R_{c} . R_{c}$ depends on the following parameters

$$
R_{c}=f\left(n, \rho, c_{p}, T_{a d}, E_{a},(d T / d x)_{\max }, \lambda, \mu, D_{H_{2}}, D_{O_{2}}\right),
$$

where $n$ is wavenumber; $\rho, c_{p}, \lambda, \mu$ are respectively the density, heat capacity at constant pressure, thermal conductivity and dynamic viscosity of the reactive mixture; $D_{H_{2}}, D_{\mathrm{O}_{2}}$ are the mass diffusion coefficients relating the diffusive fluxes to gradients in the $\mathrm{H}_{2}$ and $\mathrm{O}_{2}$ mole fraction fields. From Equation 7, it is seen that the prediction of $R_{c}$ depends on thermodynamics $\left(\rho, c_{p}, T_{a d}\right)$, kinetics $\left(E_{a},(d T / d x)_{\max }\right)$ and transport $\left(\lambda, \mu, D_{H_{2}}, D_{\mathrm{O}_{2}}\right)$ parameters. The commonly used logarithmic sensitivity factor 
which indicates the effect of change in $i^{\text {th }}$ parameter on computed $R_{c}$ was employed $[50]:$

$$
S_{i}=\frac{\ln \left(R_{c}^{\prime}\right)-\ln \left(R_{c}^{\prime \prime}\right)}{\ln \left(z_{i}^{\prime}\right)-\ln \left(z_{i}^{\prime \prime}\right)},
$$

where $z_{i}^{\prime}$ and $z_{i}^{\prime \prime}$ are the perturbed values of the $i^{\text {th }}$ parameter shown in Equation 7; $R_{c}^{\prime}$ and $R_{c}^{\prime \prime}$ are the corresponding predicted output with the altered $i^{\text {th }}$ parameter. $z_{i}^{\prime}$ and $z_{i}^{\prime \prime}$ were set at 1.1 and 0.9 times of their nominal value. $S$ is therefore showing the linear approximation of the effects of parameter changes on the model solutions. An in-house Matlab code was developed to execute the calculation with the thermokinetics and transport properties obtained through Cantera. The mechanism used for this analysis was Wang's model [39]. Then, all the sensitivity coefficients obtained for the same initial condition were normalized by the maximum absolute value among them to clearly compare the relative contributions of the parameters on predicted $R_{c}$.

\subsubsection{Uncertainty quantification}

On the basis of local sensitivity analysis, uncertainty propagation resulting from input model parameter can be explored if its uncertainty range is known. However, we noticed that most properties in Equation 7 cannot be obtained directly from the input chemistry set (containing species and reactions descriptions, thermodynamics, and transport data). To explore the uncertainty on the predicted $R_{c}$, we have chosen to study the uncertainty propagation of the kinetics, thermodynamics, and transport properties of $\mathrm{H}$ atom. The reason of targeting $\mathrm{H}$ atom is that it is one of the most studied reactive species and the most efficient chain carrier in hydrocarbon and hydrogen oxidation [3, 48]. Note that given the large amount of calculations required to determine the uncertainty related to $\mathrm{H}$ atom only, i.e. approximately 100,000 , the uncertainty propagation for the parameters of the other species of the $\mathrm{H}_{2}-\mathrm{O}_{2}$ chemical system were not investigated.

To be consistent with the tailoring procedure and the local sensitivity analysis, Wang's mechanism was used as the basic model [39]. For the kinetics input, we chose the rate coefficients of $\mathrm{H}+\mathrm{O}_{2} \rightarrow \mathrm{OH}+\mathrm{O}$ reaction. This reaction is a chain 
branching reaction controlling the level of the radical pool during the combustion of hydrogenated fuels in $\mathrm{O}_{2}$ or air [49]. Many experimental data about this rate constant are available [51, 52]. From the definition of uncertainty factor in Wang's model, it is assigned to the pre-exponential factor $A$. For the thermodynamics input, the enthalpy of formation for $\mathrm{H}$ atom was selected. The effect of the uncertainty on entropy was not investigated because it would also modify the kinetics through the calculation of the backward reaction rate. The standard enthalpy of the $\mathrm{k}^{\text {th }}$ species $\left(H_{k}^{0}\right)$ is given by

$$
H_{k}^{0}=R\left(a_{1 k} T+\frac{a_{2 k} T^{2}}{2}+\frac{a_{3 k} T^{3}}{3}+\frac{a_{4 k} T^{4}}{4}+\frac{a_{5 k} T^{5}}{5}+a_{6 k}\right),
$$

where $T$ is the temperature in Kelvin; $a_{1 k}$ to $a_{6 k}$ are the NASA polynomial fitting coefficients. Previous works have determined $H_{k}^{0}$ at $298.15 \mathrm{~K}$ theoretically and experimentally [53-55]. Since uncertainty over a wide range of temperature is not available, the deviation is presumed to be the same as the deviation at $298.15 \mathrm{~K}$. The effect of the uncertainty on the thermodynamics was investigated by perturbing $a_{6 k}$. For the transport input, the Lennard-Jones potential well depth $\varepsilon$ in $\mathrm{cm}^{-1}$ and collision diameter $\sigma_{t}$ in $\AA$ of $\mathrm{H}$ atom were selected.

The uncertainty of the studied parameters are assumed to be characterized by log-normal distributions. Each uncertain parameter can be normalized into a nondimensional variable $x_{i}$, which follows the normal distribution,

$$
x_{i}=\frac{\ln \left(p_{i} / p_{i, 0}\right)}{\ln f_{i}},
$$

where $p_{i}$ is the value of the $i^{\text {th }}$ parameter we selected; $p_{i, 0}$ is its nominal value; and $f_{i}$ is the uncertainty factor. This uncertainty characterization method has been widely employed in evaluating the kinetics-induced uncertainty and in optimizing kinetics models $[50,56]$. After determining the distribution of $x_{i}$, Monte Carlo sampling was used based on Equation 10 to generate new inputs. Monte Carlo analysis required 10,000 runs for each tailored composition. An in-house Matlab routine was developed to rewrite chemical models, applying the altered input parameters, and then calculate the corresponding $R_{c}$. 
The nominal value and uncertainty factor of $A$ were obtained from Wang's model [39]. A two-standard deviation uncertainty in $A$ was used. Wang et al. [50] pointed out that the choice for the distribution for rate coefficient does not influence the forward uncertainty propagation projections significantly. The $f_{i}$ of $a_{6 k}$ was determined based on [55] which showed the experimentally measured enthalpy of formation for $\mathrm{H}$ atom is $217.998 \pm 0.006 \mathrm{~kJ} / \mathrm{mol}$ at $298.15 \mathrm{~K}$. The deviation between theoretical and experimental $H_{k}^{0}$ of $\mathrm{H}$ atom can be up to $1.4 \mathrm{~kJ} / \mathrm{mol}$ which is much larger than the experimental uncertainty [53]. A one-standard deviation uncertainty in $a_{6 k}$ was considered. The uncertainty range of transport parameters was determined based on the calculations done by Jasper et al. [57]. In [57], calculated Lennard-Jones parameters for $\mathrm{H}$ atom in a He bath obtained using different intermolecular potentials and for several normal hydrocarbons in several bath gases were compared with the ones from CHEMKIN transport database [58]. The effect of different baths on $\mathrm{H}$ atom was assumed to be the same as the one observed for small hydrocarbons. Considering different intermolecular potential, the maximum uncertainty factors for $\varepsilon$ and $\sigma_{t}$ for $\mathrm{H}-\mathrm{He}$ are 1.5 and 10, respectively. To account for different bath gases, we used the average value obtained for $\mathrm{He}$ and $\mathrm{N}_{2}$; the maximum uncertainty factors for $\varepsilon$ and $\sigma_{t}$ are 1.1 and 2, respectively. After comparing the effects of intermolecular potential and bath gas, we selected 1.5 and 10 to be the uncertainty factor of $\varepsilon$ and $\sigma_{t}$, respectively. A two-standard deviation uncertainty in $\sigma_{t}$ was used. A threestandard deviation uncertainty in $\varepsilon$ was used due to its large uncertainty factor. The nominal value, uncertainty factor and distribution for selected parameters are listed in Table 2.

\section{Results and discussion}

\subsection{Experimental results and model performance}

\subsubsection{Critical radius for cellularity onset}

As the SEF propagates, a cellular structure would develop possibly from the initial perturbation induced by the electrodes and progressively cover the flame surface. The development of the cellular structure is accompanied by apparent oscillations of the flame speed as the cells undergo successive phases of growth and break-up. 
Table 2: Nominal value, uncertainty factor and deviation for rate coefficients of $\mathrm{H}+\mathrm{O}_{2} \rightarrow \mathrm{OH}+\mathrm{O}$ reaction, the enthalpy of formation, the Lennard-Jones potential well depth and collision diameter of $\mathrm{H}$ atom.

\begin{tabular}{cccc}
\hline Parameter, $p_{i}$ & $p_{i, 0}$ & $f_{i}$ & Deviation \\
\hline$A$ & $2.644 \mathrm{E}+016$ & 1.15 & $2-\sigma$ \\
$a_{6 k}$ & $2.547365990 \mathrm{E}+004$ & 1.00023554 & $1-\sigma$ \\
$\varepsilon$ & 145.00 & 10.00 & $3-\sigma$ \\
$\sigma_{t}$ & 2.05 & 1.50 & $2-\sigma$ \\
\hline
\end{tabular}

Because determining the critical radius for cellularity onset through a visual inspection can lead to a subjective interpretation, we have chosen not to rely on such an approach. We defined the critical radius as the last flame radius $\left(R_{f, U}\right)$ that we employed in our flame speed analysis. As a consequence, the $R_{c}$ values that we are reporting correspond to the maximum flame radius for which the flame propagation is not affected by the development of the cellular flame front. These values are reported in Table 1 .

Fig. 6 shows the evolution of the ratio $R_{c}^{e x} / R_{c}^{t h}$ with equivalence ratio for the three investigated pressures. The uncertainty on $R_{c}^{e x}$ is $\pm 0.3 \mathrm{~mm}$. This ratio ranges between 0.29 and 0.84 , which indicates that the theory of Matalon over-estimates the critical radius for cellularity onset. Helium addition in the mixture has little effect on the deviation ratio. It is also noteworthy that the deviation is lower at 80/100 $\mathrm{kPa}$ as compared to the one observed at $50 \mathrm{kPa}$. It is noted that, at low pressure, $R_{c}^{t h}$ was predicted to be very large. For example, for rich $\mathrm{H}_{2}$-air mixture at $50 \mathrm{kPa}$, $R_{c}^{\text {th }}$ was predicted to be greater than $20 \mathrm{~cm}$. The large discrepancy observed at low pressure indicate that either the destabilizing effect of the hydrodynamic instability is under-estimated and/or that the stabilizing action of the thermo-diffusive effects are over-estimated. It also noted that, at low pressure, the accuracy of the stability theory may be compromised since it assumes that the flame thickness is negligible whereas experimentally, the flame thickness is significant under such conditions. Nevertheless, it is not clear from the experimental results what is the relationship 


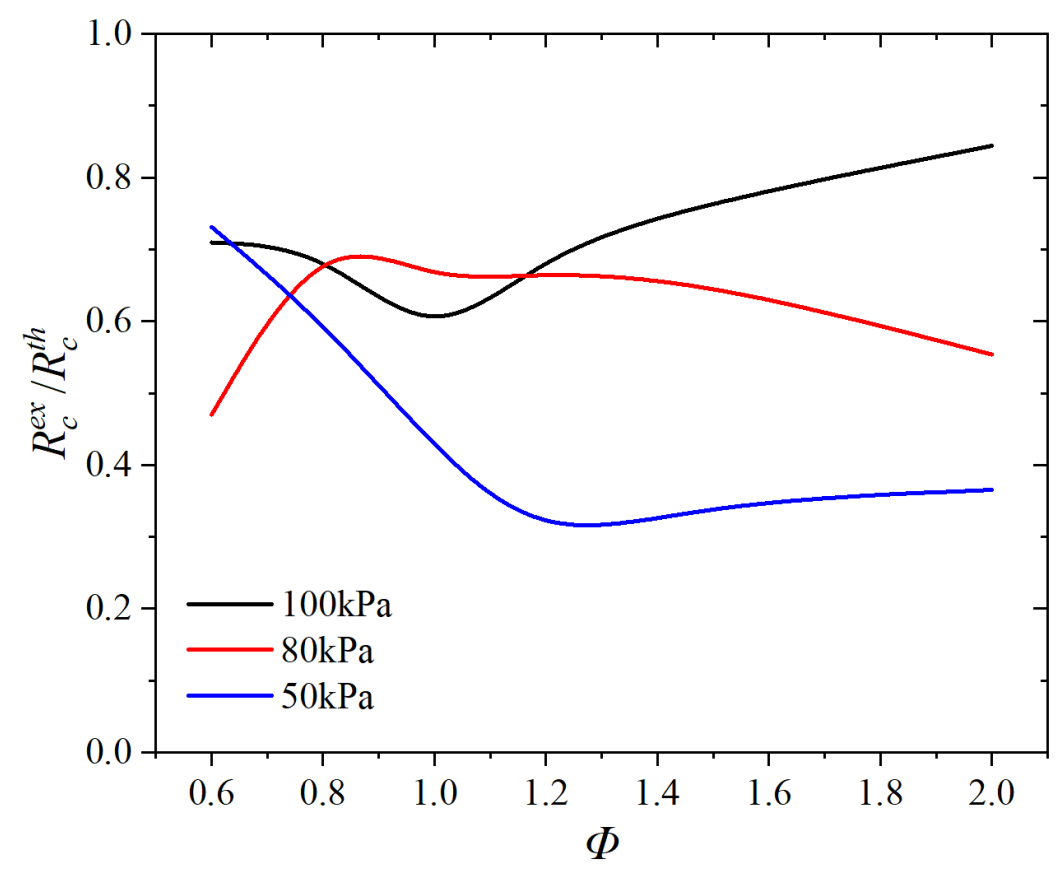

Fig. 6. Deviation of the experimental critical radius $R_{c}^{e x}$ from the theoretical one $R_{c}^{\text {th }}$ for $\mathrm{H}_{2} / \mathrm{O}_{2} / \mathrm{N}_{2} / \mathrm{He}$ mixtures at $\mathrm{T}=300 \mathrm{~K}$ and $\mathrm{P}=50 / 80 / 100 \mathrm{kPa}$.

between the flame thickness and the accuracy of the theory. For example, at $\mathrm{P}=50$ $\mathrm{kPa}$, the smallest and largest discrepancies were respectively observed at $\Phi=0.6$ and 1.2 , whereas the flame thickness is larger at $\Phi=0.6$ than at $\Phi=1.2$. The change of activation energy with equivalence ratio might also decrease locally the accuracy of the prediction since the high activation energy assumption might not be completely respected under some conditions. The experimental critical radius was related to the initial schlieren image, see Fig. 3. The surface of the flame has been covered with wrinkles at early stage of propagation due to the ignition effect. During the initial growth of the instability, the flame propagation velocity is not significantly affected which indicates that the flame surface area has not been significantly modified by the cellular structure. The data extracted during this period may still be usable to extract the unstretched flame speed. Although under certain conditions, the theory of Matalon predicts with good accuracy the critical radius (or Peclet number) for cellularity onset, discrepancies of up to a factor of 4 between the predicted and measured critical radius were previously reported by Law et al. [36], consistent with the present results. 


\subsubsection{Laminar flame speed and reaction model performance}

The position of the experimental data points in the diagram of extrapolationinduced uncertainty established by Huo et al. [26] is shown in Fig. 7. The uncertainty related to the extrapolation to zero stretch-rate is below $2 \%$ (black area) which reveals the relevance of the mixture properties tailoring and data reduction procedures we applied. Since $R_{f, U}$ in the present study is relatively larger than the upper bound used in Huo et al. [26], most points are on the left side of the black area. Nevertheless, the uncertainty due to extrapolation is still expected to be low in this region. The overall uncertainty on the flame speed measured $\left(\Delta S_{u}^{0}\right)$ can be estimated using the formula employed by Nativel et al. [25]

$$
\Delta S_{u}^{0}=\sqrt{\left(\Delta S_{u, e x t}\right)^{2}+\left(\Delta S_{u, T}\right)^{2}+\left(\Delta S_{u, r f}\right)^{2}+\left(\Delta S_{u, r a d}\right)^{2}}
$$

where $\Delta S_{u, e x t}$ is the uncertainty due to the extrapolation to zero-stretch rate, taken equal to $2 \% ; \Delta S_{u, T}$ is the uncertainty due to the uncertainty on the temperature, taken equal to $0.4 \% ; \Delta S_{u, r f}$ is the uncertainty due to the uncertainty on the flame radii, taken equal to $0.9 \%$; and $\Delta S_{u, \text { rad }}$ is the uncertainty due to radiation, taken equal to $0.7 \%$. This analysis leads to a maximum uncertainty of $2.3 \%$.

After evaluating the performance of the flame stability theory, the experimental $S_{u}^{0}$ and $L_{b}$ were used to assess the performance of four chemical models. The relative error on $S_{u}^{0}\left(E_{r}\left(S_{u}^{0}\right)\right)$ was calculated using

$$
E_{r}\left(S_{u}^{0}\right)=\frac{\Delta S_{u}^{0}}{S_{u(E x p)}^{0}}=\frac{S_{u(C a l)}^{0}-S_{u(E x p)}^{0}}{S_{u(E x p)}^{0}},
$$

where $S_{u(E x p)}^{0}$ and $S_{u(C a l)}^{0}$ are the experimental and calculated unstretched laminar speed, respectively. Fig. 8 shows the evolution of the flame speed as a function of equivalence ratio for the three investigated pressures. At all pressures, the flame speed increases in the range $\Phi=0.6$ to $\Phi=1.5$. In the range $\Phi=1.5$ to $\Phi=2.0$, the flame speed plateaus at $\mathrm{P}=50$ and $80 \mathrm{kPa}$ and decreases at $\mathrm{P}=100 \mathrm{kPa}$. The trend can be explained by the respective changes of the mixture diffusivity and of the chemical energy release rate with equivalence ratio. All four models reproduce qualitatively the trends observed experimentally. Quantitatively, the deviation between 


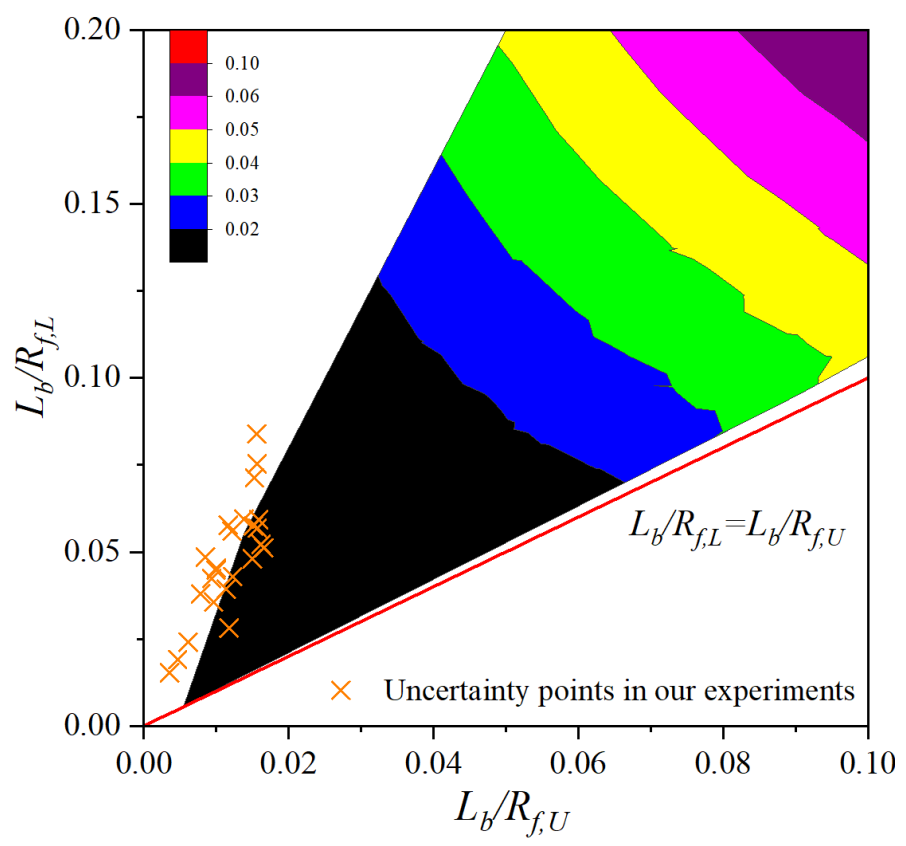

Fig. 7. Experimental data points in the map of extrapolation-induced uncertainty. The color bar presents the level of error expressed as $\Delta S_{u}^{0} / S_{u}^{0}$. Conditions: $\mathrm{H}_{2} / \mathrm{O}_{2} / \mathrm{N}_{2} / \mathrm{He}$ mixtures; $\Phi=0.6-2$; $\mathrm{P}=50-100 \mathrm{kPa} ; \mathrm{T}=293-300 \mathrm{~K}$. Further details about this uncertainty map can be found in [26].

the experiments and the different models is below 10\% except for Konnov's model for the mixtures with $\Phi=0.6$ and 0.8 at $\mathrm{P}=50 \mathrm{kPa}$. It is noted that the model of Konnov tends to over-estimate the flame speed in general whereas the model of Wang tends to under-estimate it. Curran's model performs better at $50 \mathrm{kPa}$, Burke's model performs better at $80 \mathrm{kPa}$ whereas Konnov's model performs better at $100 \mathrm{kPa}$. The mean absolute error for the models of Burke, Curran, Konnov and Wang are, $2.4 \%, 2.4 \%, 4.4 \%, 3.8 \%$, respectively. These errors are similar to the experimental uncertainty on $S_{u}^{0}$.

As the dynamical response of the flame to stretch rate is quantified by the Markstein length, we have compared the experimental and calculated values obtained for this parameter, as shown in Fig. 9. The error bars on $L_{b}$ measurements are associated with the goodness-of-fit only. Qualitatively, the models tend to better reproduce the evolution of the Markstein length with equivalence ratio at $\mathrm{P}=50$ $\mathrm{kPa}$. At higher pressures, the models essentially fail at reproducing the shape of the 


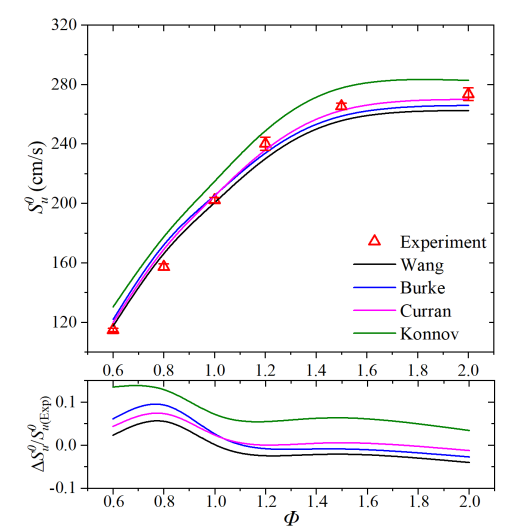

a) $\mathrm{P}=50 \mathrm{kPa}$

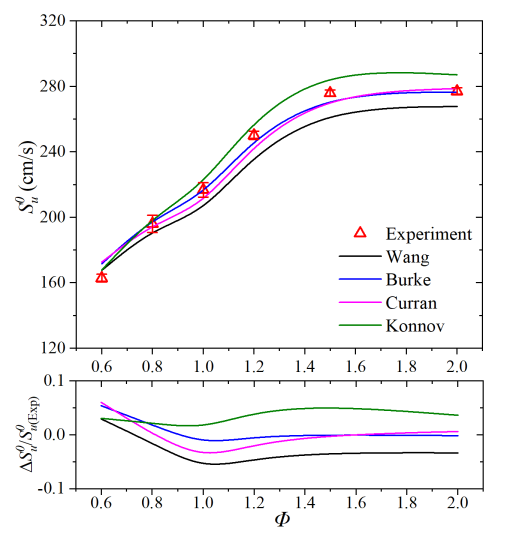

b) $\mathrm{P}=80 \mathrm{kPa}$
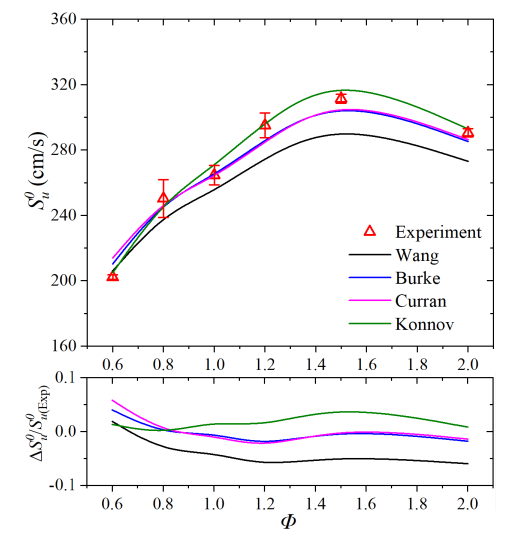

c) $\mathrm{P}=100 \mathrm{kPa}$

Fig. 8. Comparison between the experimental and calculated unstretched laminar flame speed for $\mathrm{H}_{2} / \mathrm{O}_{2} / \mathrm{N}_{2} / \mathrm{He}$ mixtures at $\mathrm{T}=300 \mathrm{~K}$ and $\mathrm{P}=50 / 80 / 100 \mathrm{kPa}$.

curve observed experimentally. It is also noted that Konnov's model fails to predict a negative Markstein length in the case for which $\Phi=0.6$ and $\mathrm{P}=50 \mathrm{kPa}$. Quantitatively, the mean absolute error on the Markstein length, calculated in the same way as the error on the flame speed, see Equation 12, for the models of Burke, Curran, Konnov and Wang are, 30.2\%, 30.0\%, 30.4\%, 26.3\%, respectively. The uncertainty on $L_{b}$ measurement is about one order of magnitude larger than that on $S_{u}^{0}$. Consequently, the errors in the prediction of the detailed models are on the same order as the uncertainty, which indicates that the predictions may actually be considered as satisfactory overall. Further efforts need to be devoted to improving the accuracy of $L_{b}$ measurement. After successfully reproducing $S_{u}^{0}$, the correct characterization of $L_{b}$ should be paid close attention to in the future reaction model development.

\subsection{Local sensitivity analysis for $R_{c}$}

Local sensitivity coefficients for critical flame radius predicted by the flame stability theory of Matalon are shown in Fig. 10. Among these parameters, $R_{c}$ is most sensitive to $T_{a d}$. It can be explained by the appearance of $T_{a d}$ in the calculation of expansion ratio and Zeldovich number. Furthermore, the expansion ratio is a basic variable that characterizes the effect of hydrodynamic and thermo-diffusive instability. $R_{c}$ is least sensitive to mixture viscosity $\mu$. This is because $Q_{3}$ is much 

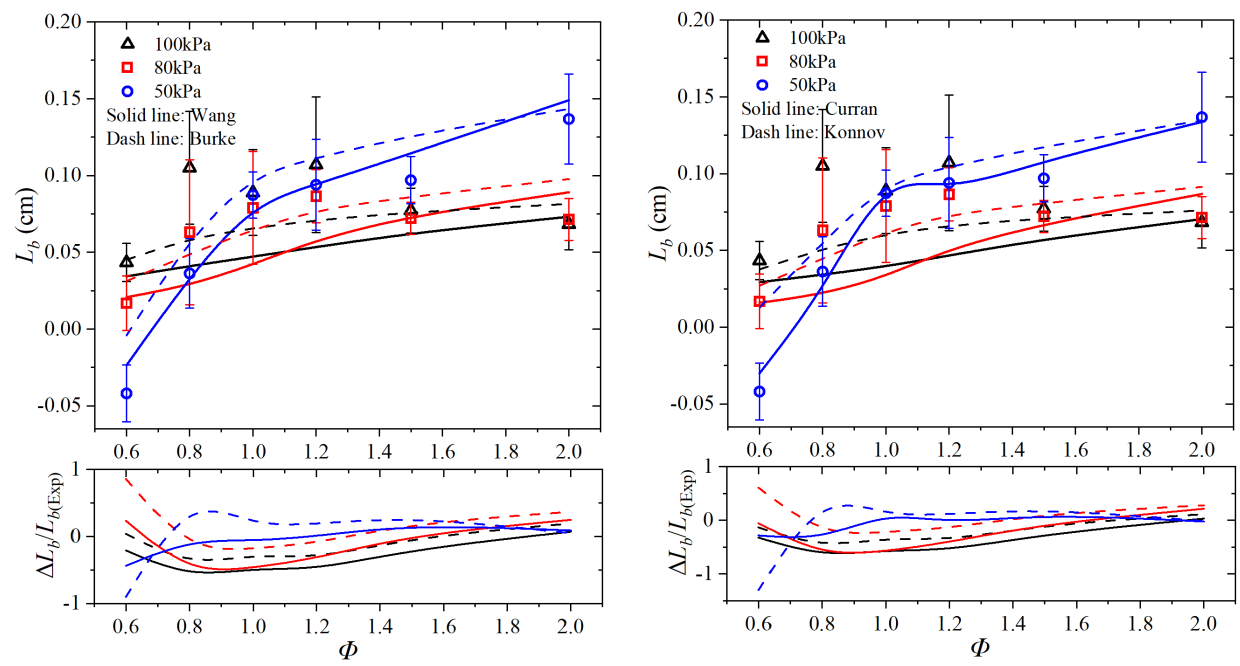

Fig. 9. Comparison between the experimental and calculated Markstein length for $\mathrm{H}_{2} / \mathrm{O}_{2} / \mathrm{N}_{2} / \mathrm{He}$ mixtures at $\mathrm{T}=300 \mathrm{~K}$ and $\mathrm{P}=50 / 80 / 100 \mathrm{kPa}$.

smaller as compared to $Q_{1}$ and $Q_{2}$ in Equation 1. As a consequence, the influence of the product of $\operatorname{Pr}$ and $Q_{3}$ to $P e_{c}$ is less significant. As expected, with the increase of equivalence ratio, the local sensitivity coefficient for $D_{H_{2}}$ and $D_{O_{2}}$ decreases and increases, respectively. This trend is caused by the corresponding mole fraction change in the fresh mixtures. Within the pressure range we studied, pressure has little effect on the sensitivity factors except for $E_{a}$. The local sensitivity coefficients for $\rho, c_{p}, \lambda$ for the lean case and $\mathrm{P}=50 \mathrm{kPa}$ are larger compared to the ones for the stoichiometric case and $\mathrm{P}=80 / 100 \mathrm{kPa}$.

It is noted that the uncertainty range for the parameters of Equation 7 are very different. For example, the adiabatic temperature usually has an uncertainty below $0.2 \%$ [49], while for $E_{a}$ the uncertainty range is relatively large as will be discussed later. Results in Fig. 10 are based on the assumption that the uncertainty range of these parameters are identical due to lack of error limits of some parameters. Actual parameter sets with reliable uncertainty values are needed in order to quantify the uncertainty of the predicted critical radius. 


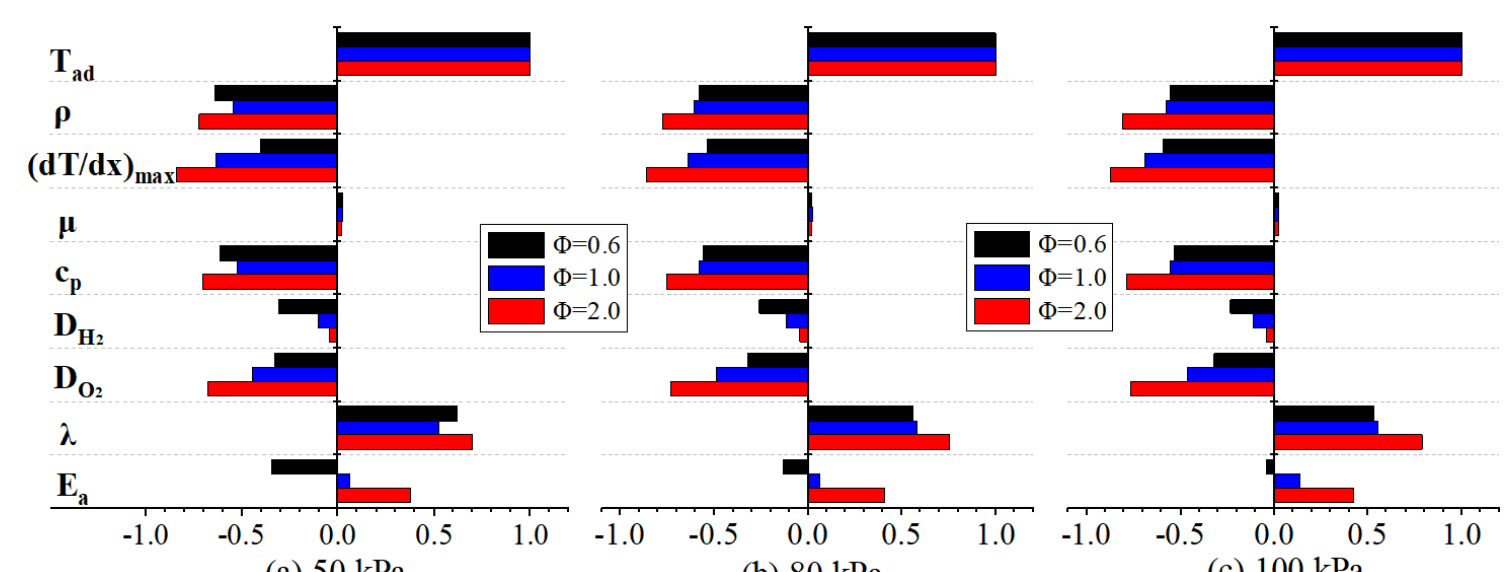

(a) $50 \mathrm{kPa}$

(b) $80 \mathrm{kPa}$

(c) $100 \mathrm{kPa}$

Sensitivity factor

Fig. 10. Local sensitivity analysis on $R_{c}$ for $\mathrm{H}_{2} / \mathrm{O}_{2} / \mathrm{N}_{2} / \mathrm{He}$ mixtures at $\mathrm{T}=300 \mathrm{~K}$ and $\mathrm{P}=50 / 80 / 100 \mathrm{kPa}$.

\subsection{Uncertainty propagation analysis for $R_{c}$}

Using Monte Carlo sampling, the uncertainty propagation was investigated assuming log-normal distributed input parameters. The results obtained for the tailored composition at $\mathrm{P}=100 \mathrm{kPa}$ are shown in Fig. 11. The relative frequency histograms and fitted probability distributions of $R_{c}$ for the three equivalence ratios are shown in Fig. 12. The fitted mathematical expectations and variances are listed in Table 3. As seen in Fig. 11, the uncertainties on transport properties $\varepsilon$ and $\sigma_{t}$ lead to larger uncertainty on $R_{c}$ than the uncertainties on the kinetic and thermodynamic parameters. The variance induced by the uncertainty on $a_{6 k}$ is the smallest among these four studied parameters. The present results are consistent with the previous study by Zador et al. [48] which showed that the kinetic contributions to the overall uncertainty on laminar flame speed and the maximum concentration of $\mathrm{H}, \mathrm{O}$ and $\mathrm{OH}$ radicals are more significant than the thermodynamic contributions. This is due to the higher accuracy of thermodynamic data as compared to the kinetics parameters. Connecting the uncertainty factor in Table 2 to the standard deviation results, we noticed that although $\varepsilon$ demonstrates the largest $f$, its uncertainty does not lead to the widest $R_{c}$ range. The widest $R_{c}$ range comes from the uncertainty on $\sigma_{t}$ which indicates that the collision diameter has a more significant impact on the calculation of the transport parameters, i.e. thermal conductivity and mass dif- 
fusivity and thus alter the Lewis and Prandtl numbers. With the mixture changing from lean to rich, the standard deviations resulting from the uncertainties of $A, \varepsilon$ and $\sigma_{t}$ are increasing while for $a_{6 k}$ the maximum standard deviation is located at $\Phi=1.5$ and the minimum standard deviation is located at $\Phi=1.2$. Previous studies by Wang et al. [50,59] show the great potential of uncertainty quantification based on log-normal distributions of rate constants. From Fig. 12, log-normal distribution is also an appropriate method for uncertainty characterization for transport parameters.

The combined uncertainty stemming from the rate coefficients of $\mathrm{H}+\mathrm{O}_{2} \rightarrow \mathrm{OH}+$ $\mathrm{O}$ reaction, thermodynamics and transport parameters for $\mathrm{H}$ atom can be calculated using the equation employed by Xiouris et al. [7]

$$
\sigma_{R_{c}}=\sqrt{\left(\sigma_{A}\right)^{2}+\left(\sigma_{a_{6 k}}\right)^{2}+\left(\sigma_{\varepsilon}\right)^{2}+\left(\sigma_{\sigma_{t}}\right)^{2}}
$$

where $\sigma_{R_{c}}$ is the total uncertainty on $R_{c} ; \sigma_{A}, \sigma_{a_{6 k}}, \sigma_{\varepsilon}, \sigma_{\sigma_{t}}$ are the fitted standard deviation of four selected parameters. Errors of different parameters are assumed to be independent. The calculated $\sigma_{R_{c}}$ are listed in Table 3 .

As seen in Table 3, the final uncertainty on $R_{c}$ prediction is no better than $10 \%$ with $95 \%$ confidence interval. Only the uncertainties on $\mathrm{H}$ atom were considered. In addition, the above discussion is based on the assumption that the calculated activation energy data is accurate. However, the numerical and experimental global $E_{a}$ for $\mathrm{H}_{2}$-air mixtures have been compared in [17] and relative errors of up to $40 \%$ have been demonstrated. Further experimental determination of $E_{a}$ would be needed to improve the predictions of $R_{c}$. The results of Grosseuvres et al. have been reproduced in the supplemental material of the present paper. The present results demonstrate that (i) the critical radius for cellularity onset predicted by the stability theory of Matalon is affected by a significant uncertainty due to the uncertainty on the input parameters; and (ii) the accuracy of the theoretical critical radius may be improved as more accurate input parameters become available in the literature. 


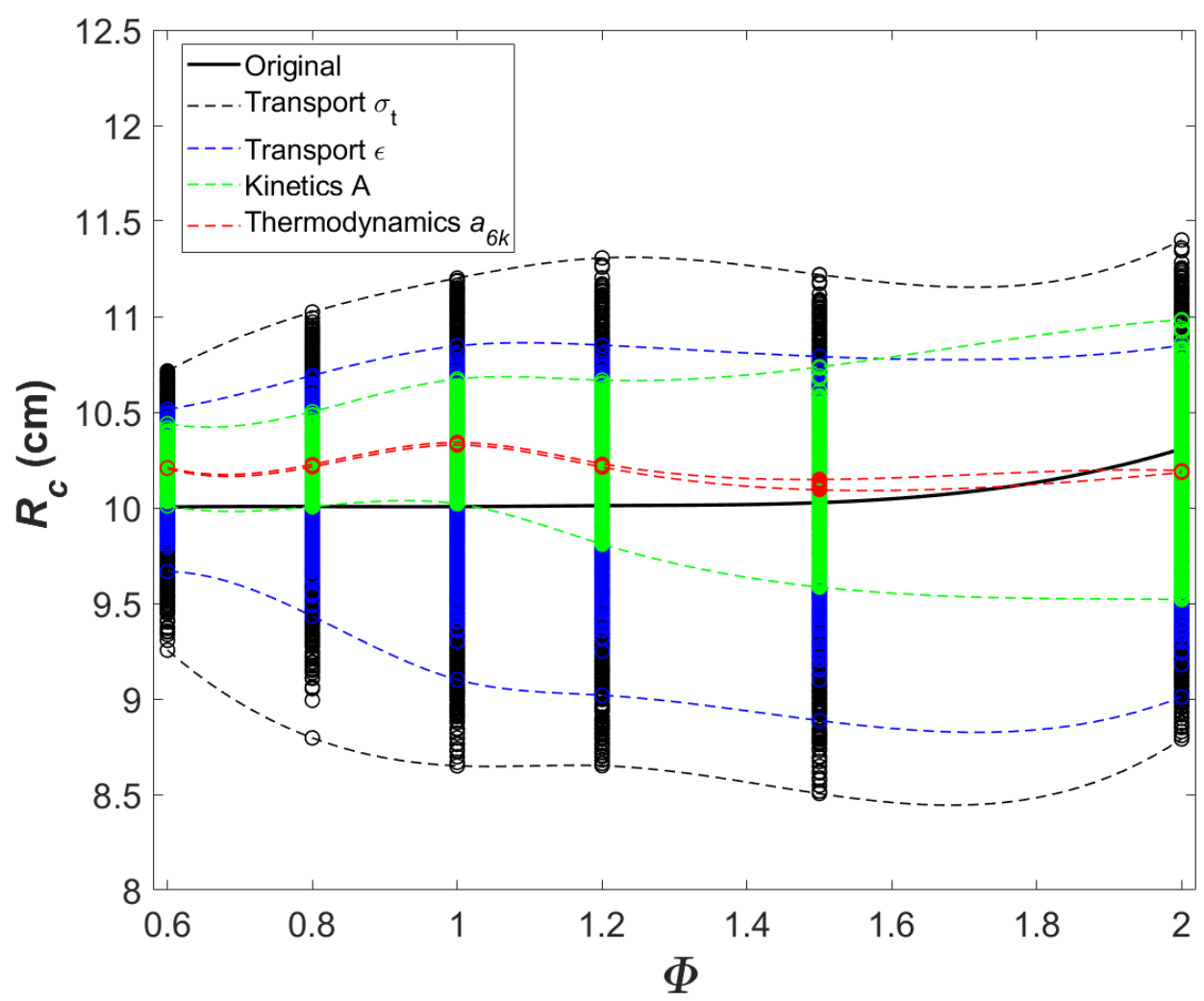

Fig. 11. Scatter plot showing the uncertainty propagation from input parameters to $R_{c}$ for tailored $\mathrm{H}_{2} / \mathrm{O}_{2} / \mathrm{N}_{2} /$ He mixtures at $\mathrm{P}=100 \mathrm{kPa}$.

\section{Conclusion}

Using large flame radius is an efficient way to minimize the extrapolation-induced uncertainty in laminar flame speed measurement. In order to obtain more data by limiting flame instability, a numerical implementation of the flame stability theory of Matalon et al. has been employed to tailor the mixture properties. This method was applied to $\mathrm{H}_{2}$-air mixtures with equivalence ratios from 0.6 to 2.0 , at $\mathrm{T}=300$ $\mathrm{K}$ and $\mathrm{P}=50 / 80 / 100 \mathrm{kPa}$. Comparing the theoretical and experimental results, we can see that over-estimation for $R_{c}$ is obvious at all pressures and equivalence ratios. Especially at $50 \mathrm{kPa}$, the ratio between experimental $R_{c}$ to the theoretical one can be as low as 0.27 at $\Phi=1.2$. Although the experimental critical radius was found to be significantly lower than the theoretical one, SEFs without cellular structure at large radius were obtained with a total uncertainty on $S_{u}^{0}$ below $2.3 \%$. 
Table 3: Fitted normally distributed probability density function of $R_{c}$ for tailored $\mathrm{H}_{2} / \mathrm{O}_{2} / \mathrm{N}_{2} / \mathrm{He}$ mixtures at $\mathrm{P}=100 \mathrm{kPa}$.

\begin{tabular}{|c|c|c|c|c|c|c|c|c|c|}
\hline \multirow[b]{2}{*}{$\Phi$} & \multicolumn{2}{|c|}{ Kinetics $A$} & \multicolumn{2}{|c|}{ Thermodynamics $a_{6 k}$} & \multicolumn{2}{|c|}{ Transport $\varepsilon$} & \multicolumn{2}{|c|}{ Transport $\sigma_{t}$} & \multirow{2}{*}{$\begin{array}{c}\text { Total } \\
\sigma_{R_{c}}\end{array}$} \\
\hline & $\mu$ & $\sigma$ & $\mu$ & $\sigma$ & $\mu$ & $\sigma$ & $\mu$ & $\sigma$ & \\
\hline 0.6 & 10.205 & 0.051 & 10.208 & $7.78 \mathrm{E}-04$ & 10.179 & 0.079 & 10.227 & 0.212 & 0.232 \\
\hline 0.8 & 10.223 & 0.065 & 10.220 & $5.38 \mathrm{E}-04$ & 10.232 & 0.148 & 10.240 & 0.293 & 0.335 \\
\hline 1.0 & 10.320 & 0.056 & 10.339 & $1.11 \mathrm{E}-03$ & 10.305 & 0.154 & 10.356 & 0.363 & 0.398 \\
\hline 1.2 & 10.228 & 0.112 & 10.226 & $9.34 \mathrm{E}-05$ & 10.245 & 0.202 & 10.225 & 0.361 & 0.428 \\
\hline 1.5 & 10.064 & 0.162 & 10.103 & $5.58 \mathrm{E}-03$ & 10.171 & 0.220 & 10.098 & 0.384 & 0.471 \\
\hline 2.0 & 10.182 & 0.189 & 10.192 & $1.26 \mathrm{E}-03$ & 10.252 & 0.228 & 10.178 & 0.376 & 0.478 \\
\hline
\end{tabular}

Four models were assessed with respect to the unstretched laminar flame speed and the Markstein length using unsteady numerical simulation. The error on both quantities were close to the experimental uncertainties although some of the qualitative trends could not be reproduced for the Markstein length.

Further investigations on $R_{c}$ predictions were performed through local sensitivity analysis and uncertainty quantification using Monte Carlo sampling. Important flame properties from the flame stability theory were identified. The largest and smallest effects come from the change of adiabatic temperature and mixture viscosity, respectively. Uncertainty quantification was focused on the effect of the uncertainty on the kinetics, thermodynamics, and transport parameters of the $\mathrm{H}$ atom. The variances of the calculated $R_{c}$ are arranged in descending order: collision diameter $\sigma_{t}$, Lennard-Jones potential well depth $\varepsilon$, pre-factor $A$ of $\mathrm{H}+\mathrm{O}_{2} \rightarrow \mathrm{OH}+\mathrm{O}$ reaction, thermodynamic polynomial coefficient $a_{6 k}$ of $\mathrm{H}$ atom. Transport-induced uncertainty is obvious which reveals the significance of accurate transport data. We believe that more precise critical radius predictions could be achieved if some of the parameters, in particular the activation energy, would be measured experimentally instead of being calculated.

\section{Acknowledgments}


The present study was founded by the Natural Science Foundation of China under grant number 51750110502 and the Programme Investissement d'Avenir-MITHYGENE grant agreement no. ANR-11-RSNR-0015. RM was also supported by a start-up fund of the Center for Combustion Energy of Tsinghua University. RM is grateful to the French Labex CAPRYSSES program, grant agreement no. ANR-11-LABX0006-01, for supporting his visit at ICARE-CNRS Orléans as a visiting professor. 

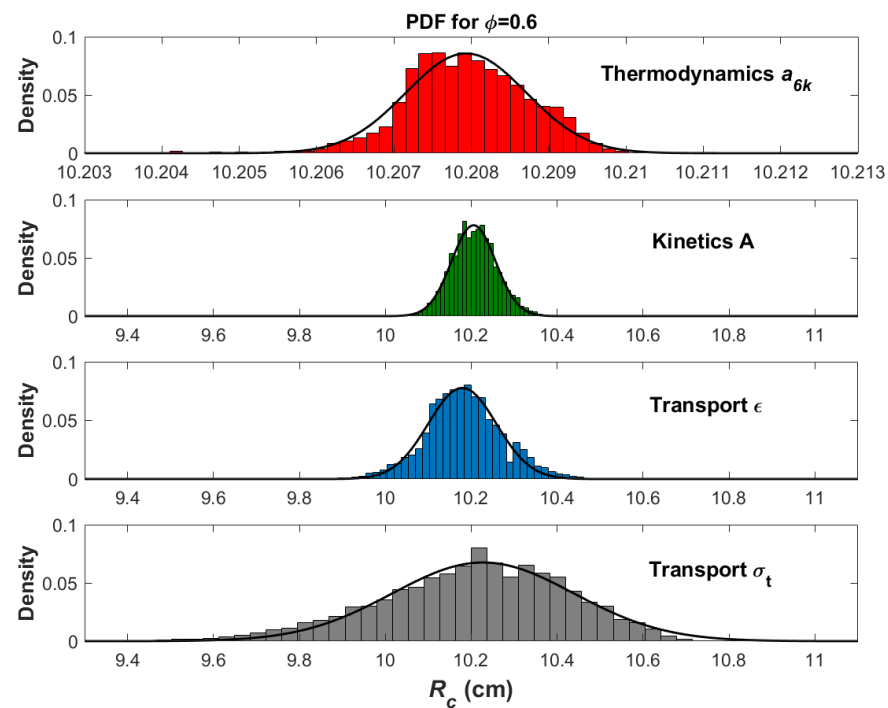

PDF for $\phi=1.0$
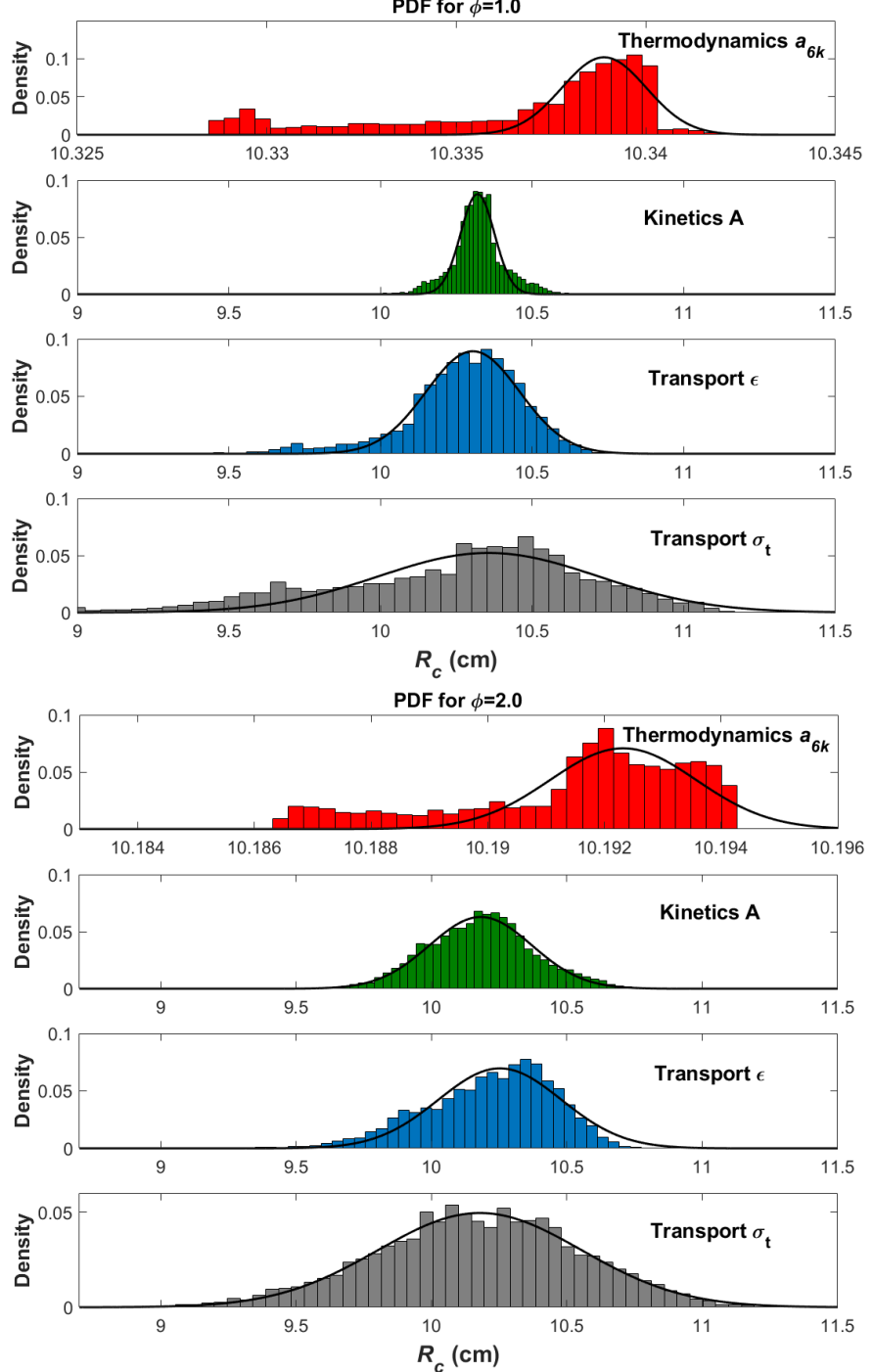

Fig. 12. Relative frequency histograms and fitted normally distributed probability density function of $R_{c}$ at $\Phi=0.6 / 1.0 / 2.0$ and $\mathrm{P}=100 \mathrm{kPa}$. 
[1] F. Egolfopoulos, N. Hansen, Y. Ju, K. Kohse-Hoinghaus, C. Law, F. Qi, Advances and challenges in laminar flame experiments and implications for combustion chemistry, Progress in Energy and Combustion Science 43 (2014) 36-67. doi:10.1016/j.pecs. 2014.04.004.

[2] A. A. Konnov, A. Mohammad, V. R. Kishore, N. I. Kim, C. Prathap, S. Kumar, A comprehensive review of measurements and data analysis of laminar burning velocities for various fuel+air mixtures, Progress in Energy and Combustion Science 68 (2018) 197-267. doi:https://doi.org/10 .1016/j.pecs .2018.05. 003.

[3] C. K. Law, Combustion Physics, Cambridge University Press, 2010.

[4] S. Lapointe, G. Blanquart, Fuel and chemistry effects in high Karlovitz premixed turbulent flames, Combustion and Flame 167 (2016) 294-307. doi: https://doi.org/10.1016/j.combustflame.2016.01.035.

[5] L. Boeck, S. Lapointe, J. Melguizo-Gavilanes, G. Ciccarelli, Flame propagation across an obstacle: OH-PLIF and 2-D simulations with detailed chemistry, Proceedings of the Combustion Institute 36 (2) (2017) 2799-2806. doi : https: //doi.org/10.1016/j.proci.2016.06.097.

[6] L. Boeck, M. Kellenberger, G. Rainsford, G. Ciccarelli, Simultaneous OH-PLIF and schlieren imaging of flame acceleration in an obstacle-laden channel, Proceedings of the Combustion Institute 36 (2) (2017) 2807-2814. doi:https: //doi.org/10.1016/j.proci.2016.06.096.

[7] C. Xiouris, T. Ye, J. Jayachandran, F. N. Egolfopoulos, Laminar flame speeds under engine-relevant conditions: Uncertainty quantification and minimization in spherically expanding flame experiments, Combustion and Flame 163 (2016) 270-283. doi:https://doi.org/10.1016/j.combustflame.2015.10.003.

[8] Z. Chen, On the accuracy of laminar flame speeds measured from outwardly propagating spherical flames: Methane/air at normal temperature and pres- 
sure, Combustion and Flame 162 (6) (2015) 2442-2453. doi:10.1016/j. combustflame.2015.02.012.

[9] A. N. Lipatnikov, S. S. Shy, W. Li, Experimental assessment of various methods of determination of laminar flame speed in experiments with expanding spherical flames with positive Markstein lengths, Combustion and Flame 162 (7) (2015) 2840-2854. doi:10.1016/j.combustflame.2015.04.003.

[10] J. Beeckmann, R. Hesse, J. Schaback, H. Pitsch, E. Varea, N. Chaumeix, Flame propagation speed and Markstein length of spherically expanding flames: Assessment of extrapolation and measurement techniques, Proceedings of the Combustion Institute 37 (2) (2019) 1521-1528. doi:https://doi.org/10. 1016/j.proci.2018.08.047.

[11] Z. Chen, M. P. Burke, Y. Ju, Effects of Lewis number and ignition energy on the determination of laminar flame speed using propagating spherical flames, Proceedings of the Combustion Institute 32 (1) (2009) 1253-1260. doi : https: //doi.org/10.1016/j.proci.2008.05.060.

[12] Z. Chen, M. P. Burke, Y. Ju, On the critical flame radius and minimum ignition energy for spherical flame initiation, Proceedings of the Combustion Institute 33 (1) (2011) 1219-1226. doi:10.1016/j.proci.2010.05.005.

[13] Z. Chen, Effects of radiation and compression on propagating spherical flames of methane/air mixtures near the lean flammability limit, Combustion and Flame 157 (12) (2010) 2267-2276. doi:10.1016/j.combustflame.2010.07.010.

[14] Z. Chen, Effects of radiation absorption on spherical flame propagation and radiation-induced uncertainty in laminar flame speed measurement, Proceedings of the Combustion Institute 36 (1) (2017) 1129-1136. doi:10.1016/j. proci.2016.05.003.

[15] M. Zhou, G. Li, J. Liang, H. Ding, Z. Zhang, Effect of ignition energy on the uncertainty in the determination of laminar flame speed using outwardly 
propagating spherical flames, Proceedings of the Combustion Institute 37 (2) (2019) 1615-1622. doi:10.1016/j.proci.2018.07.084.

[16] M. P. Burke, Z. Chen, Y. Ju, F. L. Dryer, Effect of cylindrical confinement on the determination of laminar flame speeds using outwardly propagating flames, Combustion and Flame 156 (4) (2009) 771-779. doi:10.1016/j. combustflame.2009.01.013.

[17] R. Grosseuvres, A. Comandini, A. Bentaib, N. Chaumeix, Combustion properties of $\mathrm{H} 2 / \mathrm{N} 2 / \mathrm{O} 2 /$ steam mixtures, Proceedings of the Combustion Institute 37 (2) (2019) 1537-1546. doi:10.1016/j.proci.2018.06.082.

[18] S. Jerzembeck, M. Matalon, N. Peters, Experimental investigation of very rich laminar spherical flames under microgravity conditions, Proceedings of the Combustion Institute 32 (1) (2009) 1125-1132. doi:https://doi.org/10. 1016/j.proci.2008.06.211.

[19] H. Yu, W. Han, J. Santner, X. Gou, C. H. Sohn, Y. Ju, Z. Chen, Radiationinduced uncertainty in laminar flame speed measured from propagating spherical flames, Combustion and Flame 161 (11) (2014) 2815-2824. doi:10.1016/ j. combustflame.2014.05.012.

[20] A. Kelley, C. Law, Nonlinear effects in the extraction of laminar flame speeds from expanding spherical flames, Combustion and Flame 156 (9) (2009) 18441851. doi:https://doi.org/10.1016/j.combustflame.2009.04.004.

[21] A. P. Kelley, J. K. Bechtold, C. K. Law, Premixed flame propagation in a confining vessel with weak pressure rise, Journal of Fluid Mechanics 691 (2011) 26-51. doi:10.1017/jfm.2011.439.

[22] Z. Chen, On the extraction of laminar flame speed and Markstein length from outwardly propagating spherical flames, Combustion and Flame 158 (2) (2011) 291-300. doi:10.1016/j.combustflame.2010.09.001.

[23] F. Wu, W. Liang, Z. Chen, Y. Ju, C. K. Law, Uncertainty in stretch extrapolation of laminar flame speed from expanding spherical flames, Proceedings of 
the Combustion Institute 35 (1) (2015) 663-670. doi:10.1016/j ·proci. 2014. 05.065.

[24] W. Liang, F. Wu, C. K. Law, Extrapolation of laminar flame speeds from stretched flames: Role of finite flame thickness, Proceedings of the Combustion Institute 36 (1) (2017) 1137-1143. doi:10.1016/j.proci.2016.08.074.

[25] D. Nativel, M. Pelucchi, A. Frassoldati, A. Comandini, A. Cuoci, E. Ranzi, N. Chaumeix, T. Faravelli, Laminar flame speeds of pentanol isomers: An experimental and modeling study, Combustion and Flame 166 (2016) 1-18. doi:10.1016/j. combustflame.2015.11.012.

[26] J. Huo, S. Yang, Z. Ren, D. Zhu, C. K. Law, Uncertainty reduction in laminar flame speed extrapolation for expanding spherical flames, Combustion and Flame 189 (2018) 155-162. doi :https://doi .org/10.1016/j.combustflame. 2017.10 .032 .

[27] N. Lamoureux, N. Djebaïli-Chaumeix, C.-E. Paillard, Laminar flame velocity determination for $\mathrm{H}_{2}$-air-He- $\mathrm{CO}_{2}$ mixtures using the spherical bomb method, Experimental Thermal and Fluid Science 27 (4) (2003) 385-393, second Mediterranean Combustion Symposium. doi :https ://doi .org/10.1016/ S0894-1777(02) 00243-1.

[28] S. Tse, D. Zhu, C. Law, Morphology and burning rates of expanding spherical flames in $\mathrm{H}_{2} / \mathrm{O}_{2}$ /inert mixtures up to 60 atmospheres, Proceedings of the Combustion Institute 28 (2) (2000) 1793-1800. doi:https://doi.org/10.1016/ S0082-0784(00)80581-0.

[29] X. Shen, X. Yang, J. Santner, J. Sun, Y. Ju, Experimental and kinetic studies of acetylene flames at elevated pressures, Proceedings of the Combustion Institute 35 (1) (2015) 721-728. doi:https://doi.org/10.1016/j.proci.2014.05. 106.

[30] W. Zhang, X. Gou, W. Kong, Z. Chen, Laminar flame speeds of lean high- 
hydrogen syngas at normal and elevated pressures, Fuel 181 (2016) 958-963. doi:https://doi.org/10.1016/j.fuel.2016.05.013.

[31] M. Han, Y. Ai, Z. Chen, W. Kong, Laminar flame speeds of $\mathrm{H}_{2} / \mathrm{CO}$ with $\mathrm{CO}_{2}$ dilution at normal and elevated pressures and temperatures, Fuel 148 (2015) 32-38. doi:https://doi.org/10.1016/j.fuel.2015.01.083.

[32] Y. Ai, Z. Zhou, Z. Chen, W. Kong, Laminar flame speed and Markstein length of syngas at normal and elevated pressures and temperatures, Fuel 137 (2014) 339-345. doi:https://doi.org/10.1016/j.fuel.2014.08.004.

[33] R. Addabbo, J. Bechtold, M. Matalon, Wrinkling of spherically expanding flames, Proceedings of the Combustion Institute 29 (2) (2002) 1527 - 1535. doi:https://doi.org/10.1016/S1540-7489(02)80187-0.

[34] A. Istratov, V. Librovich, On the stability of gasdynamic discontinuities associated with chemical reactions. The case of a spherical flame, Astronautica Acta 14 (5) (1969) 453-467.

[35] J. Bechtold, M. Matalon, Hydrodynamic and diffusion effects on the stability of spherically expanding flames, Combustion and Flame 67 (1) (1987) 77-90. doi:https://doi .org/10.1016/0010-2180(87)90015-0.

[36] C. Law, G. Jomaas, J. Bechtold, Cellular instabilities of expanding hydrogen/propane spherical flames at elevated pressures: theory and experiment, Proceedings of the Combustion Institute 30 (1) (2005) 159-167. doi:10.1016/ j.proci.2004.08.266.

[37] M. Matalon, Flame dynamics, Proceedings of the Combustion Institute 32 (1) (2009) 57-82. doi:https://doi.org/10.1016/j.proci.2008.08.002.

[38] D. G. Goodwin, R. L. Speth, H. K. Moffat, B. W. Weber, Cantera: An object-oriented software toolkit for chemical kinetics, thermodynamics, and transport processes, https://www.cantera.org, version 2.4.0 (2018). doi: $10.5281 /$ zenodo. 1174508 . 
[39] S. G. Davis, A. V. Joshi, H. Wang, F. Egolfopoulos, An optimized kinetic model of $\mathrm{H}_{2} / \mathrm{CO}$ combustion, Proceedings of the Combustion Institute 30 (1) (2005) 1283-1292. doi:10.1016/j.proci.2004.08.252.

[40] J. Goulier, N. Chaumeix, F. Halter, N. Meynet, A. Bentaib, Experimental study of laminar and turbulent flame speed of a spherical flame in a fan-stirred closed vessel for hydrogen safety application, Nuclear Engineering and Design 312 (2017) 214-227. doi:10.1016/j.nucengdes.2016.07.007.

[41] R. Mevel, F. Lafosse, N. Chaumeix, G. Dupre, C.-E. Paillard, Spherical expanding flames in $\mathrm{H}_{2}-\mathrm{N}_{2} \mathrm{O}$-Ar mixtures: flame speed measurements and kinetic modeling, International Journal of Hydrogen Energy 34 (21) (2009) 9007-9018. doi:https://doi.org/10.1016/j.ijhydene.2009.08.054.

[42] J. Huo, A. Saha, Z. Ren, C. K. Law, Self-acceleration and global pulsation in hydrodynamically unstable expanding laminar flames, Combustion and Flame 194 (2018) 419-425. doi:10.1016/j.combustflame.2018.05.025.

[43] D. Bradley, C. Sheppart, R. Woolley, D. Greenhalgh, R. Lockett, The development and structure of flame instabilities and cellularity at low Markstein numbers in explosions, Combustion and Flame 122 (1) (2000) 195-209. doi:https://doi.org/10.1016/S0010-2180(00)00113-9.

[44] A. A. Konnov, Yet another kinetic mechanism for hydrogen combustion, Combustion and Flame 203 (2019) 14-22. doi:https://doi.org/10.1016/j. combustflame.2019.01.032.

[45] M. P. Burke, M. Chaos, Y. Ju, F. L. Dryer, S. J. Klippenstein, Comprehensive $\mathrm{H}_{2} / \mathrm{O}_{2}$ kinetic model for high-pressure combustion, International Journal of Chemical Kinetics 44 (7) (2011) 444-474. doi:10.1002/kin.20603.

[46] M. Ó. Conaire, H. J. Curran, J. M. Simmie, W. J. Pitz, C. K. Westbrook, A comprehensive modeling study of hydrogen oxidation, International Journal of Chemical Kinetics 36 (11) (2004) 603-622. doi:10.1002/kin. 20036. 
[47] T. Turányi, A. S. Tomlin, Analysis of kinetic reaction mechanisms, Springer, 2014 .

[48] J. Zador, I. G. Zsely, T. Turanyi, M. Ratto, S. Tarantola, A. Saltelli, Local and global uncertainty analyses of a methane flame model, The Journal of Physical Chemistry A 109 (43) (2005) 9795-9807. arXiv:https://doi.org/10.1021/ jp053270i, doi:10.1021/jp053270i.

[49] T. Turányi, L. Zalotai, S. Dóbé, T. Bérces, Effect of the uncertainty of kinetic and thermodynamic data on methane flame simulation results, Physical Chemistry Chemical Physics 4 (12) (2002) 2568-2578. doi:10.1039/b109154a.

[50] H. Wang, D. A. Sheen, Combustion kinetic model uncertainty quantification, propagation and minimization, Progress in Energy and Combustion Science 47 (2015) 1-31. doi:https://doi.org/10.1016/j.pecs.2014.10.002.

[51] C.-L. Yu, M. Frenklach, D. Masten, R. Hanson, C. Bowman, Reexamination of shock-tube measurements of the rate coefficient of $\mathrm{H}+\mathrm{O}_{2} \rightarrow \mathrm{OH}+\mathrm{O}$, The Journal of Physical Chemistry 98 (17) (1994) 4770-4771.

[52] Z. Hong, D. Davidson, E. Barbour, R. Hanson, A new shock tube study of the $\mathrm{H}+\mathrm{O}_{2} \rightarrow \mathrm{OH}+\mathrm{O}$ reaction rate using tunable diode laser absorption of $\mathrm{H}_{2} \mathrm{O}$ near $2.5 \mu \mathrm{m}$, Proceedings of the Combustion Institute 33 (1) (2011) 309-316.

[53] M. Saeys, M.-F. Reyniers, G. B. Marin, V. V. Speybroeck, M. Waroquier, Ab initio calculations for hydrocarbons: Enthalpy of formation, transition state geometry, and activation energy for radical reactions, The Journal of Physical Chemistry A 107 (43) (2003) 9147-9159. doi:10.1021/jp021706d.

[54] L. A. Curtiss, K. Raghavachari, P. C. Redfern, J. A. Pople, Assessment of Gaussian-2 and density functional theories for the computation of enthalpies of formation, The Journal of Chemical Physics 106 (3) (1997) 1063-1079. doi: $10.1063 / 1.473182$.

[55] B. Ruscic, J. E. Boggs, A. Burcat, A. G. Császár, J. Demaison, R. Janoschek, J. M. L. Martin, M. L. Morton, M. J. Rossi, J. F. Stanton, P. G. Szalay, P. R. 
Westmoreland, F. Zabel, T. Bérces, IUPAC Critical evaluation of thermochemical properties of selected radicals. Part I, Journal of Physical and Chemical Reference Data 34 (2) (2005) 573-656. doi:10.1063/1.1724828.

[56] J. Urzay, N. Kseib, D. F. Davidson, G. Iaccarino, R. K. Hanson, Uncertaintyquantification analysis of the effects of residual impurities on hydrogen-oxygen ignition in shock tubes, Combustion and Flame 161 (1) (2014) 1-15. doi: 10.1016/j.combustflame.2013.08.012.

[57] A. W. Jasper, J. A. Miller, Lennard-Jones parameters for combustion and chemical kinetics modeling from full-dimensional intermolecular potentials, Combustion and Flame 161 (1) (2014) 101-110. doi:10.1016/j. combustflame.2013.08.004.

[58] R. Kee, F. Rupley, J. Miller, M. Coltrin, J. Grcar, E. Meeks, H. Moffat, A. Lutz, G. Dixon-Lewis, M. Smooke, et al., CHEMKIN-PRO, Release 15105, San Diego (CA): Reaction Design Inc.

[59] D. A. Sheen, H. Wang, The method of uncertainty quantification and minimization using polynomial chaos expansions, Combustion and Flame 158 (12) (2011) 2358-2374. doi:10.1016/j.combustflame.2011.05.010. 